San Jose State University

SJSU ScholarWorks

Master's Theses

Master's Theses and Graduate Research

1991

\title{
A study of the physical and psychological disabilities of professional musicians relative to occupational role dysfunction
}

Marcia R. Dyk

San Jose State University

Follow this and additional works at: https://scholarworks.sjsu.edu/etd_theses

\section{Recommended Citation}

Dyk, Marcia R., "A study of the physical and psychological disabilities of professional musicians relative to occupational role dysfunction" (1991). Master's Theses. 188.

DOI: https://doi.org/10.31979/etd.tq2x-ks5a

https://scholarworks.sjsu.edu/etd_theses/188

This Thesis is brought to you for free and open access by the Master's Theses and Graduate Research at SJSU ScholarWorks. It has been accepted for inclusion in Master's Theses by an authorized administrator of SJSU ScholarWorks. For more information, please contact scholarworks@sjsu.edu. 


\section{INFORMATION TO USERS}

This manuscript has been reproduced from the microfilm master. UMI films the text directly from the original or copy submitted. Thus, some thesis and dissertation copies are in typewriter face, while others may be from any type of computer printer.

The quality of this reproduction is dependent upon the quality of the copy submitted. Broken or indistinct print, colored or poor quality illustrations and photographs, print bleedthrough, substandard margins, and improper alignment can adversely affect reproduction.

In the unlikely event that the author did not send UMI a complete manuscript and there are missing pages, these will be noted. Also, if unauthorized copyright material had to be removed, a note will indicate the deletion.

Oversize materials (e.g., maps, drawings, charts) are reproduced by sectioning the original, beginning at the upper left-hand corner and continuing from left to right in equal sections with small overlaps. Each original is also photographed in one exposure and is included in reduced form at the back of the book.

Photographs included in the original manuscript have been reproduced xerographically in this copy. Higher quality $6 " \mathrm{x} 9$ " black and white photographic prints are available for any photographs or illustrations appearing in this copy for an additional charge. Contact UMI directly to order.

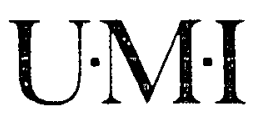

University Microfims intermational

A Bell \& Howell Information Company 300 North Zeeb Road. Ann Arbor. M! 48106-1346 USA

$313761.4700 \quad 800521.0600$ 

Order Number 1345795

\begin{abstract}
A study of the physical and psychological disabilities of professional musicians relative to occupational role dysfunction
\end{abstract}

Dyk, Marcia Ruth, M.S.

San Jose State University, 1991

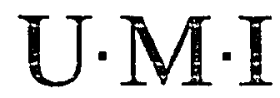

300 N. Zecb Rd.

Ann Arbor, MI 48106 



\title{
A STUDY OF THE PHYSICAL AND PSYCHOLOGICAL DISABILITIES OF PROFESSIONAL MUSICIANS \\ RELATIVE TO OCCUPATIONAL ROLE DYSFUNCTION
}

\author{
A Thesis \\ Presented to \\ The Faculty of the Department of Occupational Therapy \\ San Jose State University \\ In Partial Fulfillment \\ of the Requirements for the Degree \\ Master of Science
}

By

Marcia R. Dyk

August, 1991 
APPROVED FOR THE DEPARTMENT OF OCCUPATIONAL THERAPY

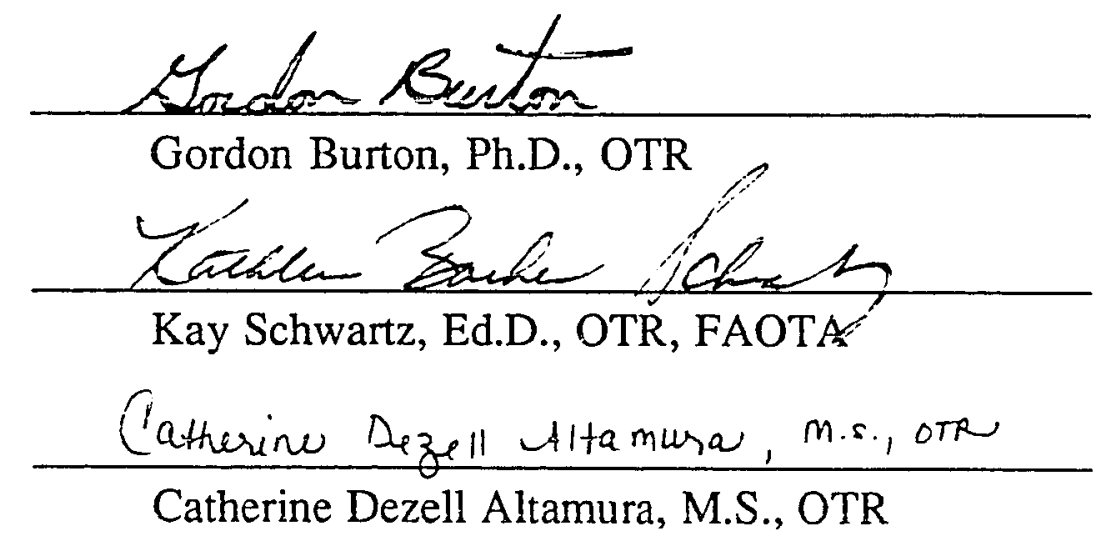

APPROVED FOR THE UNIVERSITY

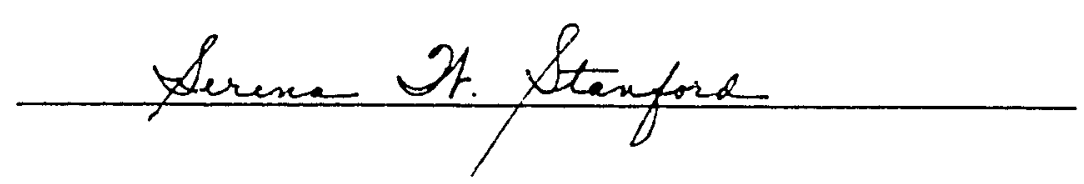




\title{
A STUDY OF THE PHYSICAL AND PSYCHOLOGICAL DISABILITIES OF PROFESSIONAL MUSICIANS RELATIVE TO OCCUPATIONAL ROLE DYSFUNCTION
}

\author{
By Marcia Dyk
}

\begin{abstract}
This study was conducted to examine which lifestyle habits and values of professional musicians were related to higher levels of physical and psychological problems. One hundred and sixty-six members of seven orchestras were surveyed. Information on demographics, daily use of time, and values relating to their idea of how much pain to tolerate and how much effort they should put forth was gathered. Physical and psychological problems, how long they had experienced the symptoms, and how these had affected their playing were reported. A previous study conducted by Dezell (1987) with a similar population and questions was unable to yield significant correlations, due to lack of diversity in the sample. In the current study, some of the habits and values were found to have a significant correlation with an increase in disabilities. The role of occupational therapy for musicians was explored, using the Model of Human Occupation.
\end{abstract}




\section{Acknowledgements}

I would like to thank my advisor, Dr. Gordon Burton, for his reassurance and direction via late night phone calls. I would like to thank Cathy Dezell, M.S., OTR for her personal support and encouragement during the development of this study. My thanks to Dr. Kay Schwartz and Dr. Lela Llorens for their careful reading of the manuscript and helpful comments.

My thanks to Jerry Evans and Sean Murray in Montana for their initial help and advice on the data analysis, and special thanks to Suzan Maresh of Oregon State University for her statistical expertise in the final stages of data analysis. My sincere thanks also to Andy Stitch for his help in producing the graphs, and assistance with my Macintosh compuier.

I would also like to thank God for his enablement in getting this thesis completed and for putting me in touch with the right people at the right time. 


\section{Table of Contents}

Page

List of Tables

List of Figures

CHAPTER 1 - INTRODUCTION

Purpose

Statement of the Problem

Objectives

Questions

Hypotheses

Definitions

Significance of the Study

Assumptions

Limitations

CHAPTER 2 - REVIEW OF THE LITERATURE

Medical Literature

Causes of Problems

Prevention of Problems

Psychological Disorders

Occupational Therapy Literature

Occupational Behavior

CHAPTER 3 - DESIGN AND METHODOLOGY

Objectives

Questions

Sample and Procedures vii

ix

1 
CHAPTER 4 - DATA AND RESULTS 32

Data Analysis Procedures 32

Descriptive Data 33

Correlational Data $\quad 50$

Results 61

CHAPTER 5 - SUMMARY, DISCUSSION AND

IMPLICATIONS FOR THE PROFESSION 65

Summary of Research Questions and Hypotheses 65

Discussion of Demographic Results 65

Discussion of Other Findings 66

Applying the Model of Human Occupation $\quad 71$

The Role of Occupational Therapy 73

Evaluation of the Injured Musician $\quad 76$

Recommendations for Further Research 76

REFERENCES

APPENDICES

A. Questionnaire 81

B. Informed Consent Letter 86

C. Resource List 88 


\section{List of Tables}

Table

Page

1. Primary Role as a Musician 34

2. Primary Instrument Played 35

3. Hours per Week Spent in Individual Practice 36

4. Time Spent Practicing Before a Break 37

5. Use of Time 39

6. Interference with Personal and Social Needs 40

7. Response to Pain/Weakness While Playing 41

8. Physical Pain Considered "Normal" in Gaining
Mastery of an Instrument

9. Amount of Personal Time Lost to Accommodate Practice Time Prior to a Concert/Audition/Competition 44

10. Amounit Wrilling to Pưsh tô Physical/Psychological Limits

11. Frequency of Reported Physical Symptoms 46

12. Frequency of Reported Psychological Symptoms 48

13. Frequency of Reported Stage Fright Related Symptoms 49

14. Reported Threat to Career 51

15. Use of Time in an Average Day Relative to Physical and Psychological Dysfunction 


\section{List of Tables, Continued}

Table Page

16. Correlation Measures for Values Relative to Physical and Psychological Dysfunction 


\section{List of Figures}

Figure Page

1. Physical/Psychological Dysfunction Relative to Length of Practice Time Before a Break

2. Physical/Psychological Dysfunction Relative to Time Spent in Leisure/Socialization

3. Physical/Psychological Dysfunction Relative to Interference with Personal/Social Needs

4. Physical/Psychological Dysfunction Relative to the Amount of Pain Considered Normal

5. Physical/Psychological Dysfunction Relative to the Degree of Pushing to One's Limits 


\section{CHAPTER 1}

\section{INTRODUCTION}

\section{Purpose of the Study}

The purpose of this study was to investigate whether a significant relationship exists between selected habits and values of instrumental musicians and the degree of reported physical and psychological problems.

\section{Statement of the Problem}

Professional musicians, like professional athletes, push themselves to the limit of the body's capabilities. Many endure pain and a high degree of psychological stress, believing it is a necessary part of the process to become and remain competitive in their field. Due to the competition, the instability, and the pressure to perform well which accompanies a professional musicians's lifestyle, many musicians feel that they must consistently push themselves to their physical and mental limits (Brandfonbrener, 1986). Such pressure often leads to physical injuries, such as overuse syndrome due to continued tissue trauma (Fry, 1986a). Psychological disturbances such as sleeplessness, depression, and substance abuse also occur.

A recently completed study of the problems of professional musicians by Dezell (1987) proposed that musicians' extreme views of acceptance of pain and need to endure long hours of practice might be 
viewed as occupational role dysfunction. Her study was one of the first to examine occupationally-related health problems of musicians relative to their internalized perceptions of the responsibilities, expectations, and pressures which accompany their lifestyle. These occupationally-based disabilities were shown to co-exist with role dysfunction in the sample selected; however, no significant correlation could be found, possibly due to the high prevalence of dysfunction found in the sample. This study attempted to re-examine similar hypotheses, with adjustments made in the sample population, questionnaire, and research design. This information may provide a foundation to address the needs of professional musicians from an occupational therapy frame of reference.

\section{Objectives}

The objectives for this study were to:

1. Determine whether a significant correlation exists between selected habits and values of professional musicians and the presence of reported work-related physical and psychlogical problems.

2. Determine whether a significant correlation exists between the musicians' values regarding effort and sacrifice and their playingrelated habits.

3. Propose recommendations for treating injured musicians, using the Model of Human Occupation. 


\section{Questions}

The research questions generated for this study were:

1. Is there a significant correlation among specific factors relative to the habits of professional musicians and an increase in physical or psychological dysfunction?

2. Is there a significant correlation between values regarding effort and sacrifice and the level of physical or psychological dysfunction?

3. Is there a significant correlation between the collective values regarding effort and sacrifice and practice-related habits?

\section{Null Hypotheses}

The null hypotheses tested in this study were :

1. There will be no significant correlation between an increase in occupationally-related physical or psychological dysfunction in professional musicians and:
a) an increase in practice time without taking a break
b) an increase in the number of hours spent playing one's instrument in an average day
c) a decrease in exercise
d) a decrease in leisure/socialization time
e) a decrease in the time spent sleeping

2. There will be no significant correlation between an increase in occupationally-related physical or psychological dysfunction in professional musicians and: 

a) an increase in how much a musician allowed playing to interfere with meeting personal and social needs
b) an increase in how much pain was considered normal to master an instrument
c) an increase in how much personal time was sacrificed to accommodate a performance or competition
d) an increase of pushing to one's physical and psychological limits

3 . There will be no significant relationship between the collective values of professional musicians regarding effort and sacrifice and the following practice-related habits:

a) time spent in individual practice

b) practicing longer sessions without taking a break

c) hours spent in playing-related work

\section{Definitions}

Conceptual Definitions:

Internalized role perceptions: images that a person holds regarding the obligations and expectations which accompany being in a certain role or position. One way in which these expectations are demonstrated is by the amount of effort and sacrifice an individual puts forth in order to accomplish his or her goals.

Occupationally-related physical disabilities: weakening, damage, or deterioration as a result of injury or disease, which is caused by or related to one's occupation. 


\section{Occupationally-related psychological disabilities: any} alterations of the mental processes, pertaining to the mind or emotions, which interfere with the expected functioning of the individual and which are caused by or related to the individual's occupation.

Occupational role dysfunction: insufficiencies in rules, skills, and habits which interfere with an individual's capacity to function in their role. Certain values such as overachieving, workaholism, and perfectionism contribute to occupational role dysfunction. A dysfunctional musician is one who may deny pain or other symptoms, work an excessive number of hours, and neglect personal and social needs. These habits and values will eventually result in an inability to fulfill the responsibilities of the role of musician.

Playing-Related Habits: routines of practicing or playing one's instrument, such as the length of time in a practice session, or the number of hours spent in playing or practicing during a day or week.

Professional musician: one who engages in practicing, rehearsing, and performing music as a primary or secondary vocation.

Values: images of what is good, right and/or important. According to Kielhofner's model (1985), values govern a person's belief about how time should be used, meaningfulness of activity, occupational goals, and personal standards for how occupations ought to be performed. 
Qperational Definitions

Internalized role perceptions: Questions 8, 10,11, and 12 of the Questionnaire (Appendix A) determine this concept (see also definition of Values Regarding Effort/Sacrifice).

Occupationally-related physical disabilities: The physical symptoms listed in Question 13 of the Questionnaire (Appendix A) describe this concept.

Occupationally-related psychological disabilities: The psychological symptoms listed in Question 14 of the Questionnaire (Appendix A) describe this concept.

Physical Dysfunction Index: This index was computed from information reported from Question 13 of the Questionnaire (Appendix A). The number of weeks a particular symptom lasted was multiplied with an estimate of the severity of the symptoms, which was determined by the percentage of time lost from practicing, playing, or performing while the symptoms persisted.

Psychological Dysfunction Index: This index was computed for each respondent from Question 14 (Appendix A) in a similar way to the physical dysfunction index; that is, by multiplying the number of weeks a particular disorder lasted with the percentage of time lost from practicing, playing, or performing.

Values Regarding Effort/Sacrifice: Questions 8, 10, 11, and 12 on the Questionnaire (Appendix A) determine this concept. These questions will provide a measure of: 
- the degree to which playing one's instrument interferes with meeting personal and social needs (Question 8).

- how much physical pain is considered normal in gaining mastery of an instrument (Question 10).

- how much personal time is lost in order to accommodate practice time (Question 11).

- how much a musician should push himself/herself to physical or psychological limits (Question 12).

\section{Significance of the Study}

Performing artists have not received adequate medical attention in the past, due to the specialized and sometimes subtle nature of their problems, and to their reticence to seek treatment (Brandfonbrener, 1986a). The population of professional musicians have a high incidence of physical and psychological problems, and as a group, have extreme ideas of what is required of them to remain competitive in their field (Fry, 1986a; Fishbein, 1988). Occupational therapy offers a potential avenue for addressing their musculoskeletal disorders, as well as assisting musicians to restructure habits, reconsider values, and strengthen coping skills so that they may live a more balanced, successful life as musicians (Goodman \& Staz, 1989; Kielhofner, 1985). 


\begin{abstract}
Assumptions
Since this researcher is a musician and has at times experienced the pressures and difficulties of that role, and has observed other musicians' difficulties, it was assumed that many musicians experience reoccurring occupationally-related physical and psychological dysfunction and have internalized role perceptions that perpetuate these problems. It was assumed that the selected sample accurately represents professional symphonic musicians. It was also assumed that the musicians responded to the questionnaire honestly, and that their answers accurately represented their ideas and conditions.
\end{abstract}

\title{
Limitations
}

Due to the constraints of time and subject availability, a sample of convenience was used. The questionnaire may not have been completed by the musicians who were fearful of submitting information regarding their physical or psychological problems, or by those with time constraints. Musicians who primarily perform with rock or jazz groups were not included. These limitations affect the generalizability of the research. 


\section{CHAPTER 2}

\section{REVIEW OF THE LITERATURE}

The mention of the maladies suffered by musicians dates back over 100 years ago in medical literature, but most articles have appeared since 1950. In the following review, the most pertinent literature was reviewed, first examining the literature dealing with the identification and prevalence of physical problems, then psychological problems, and finally, occupational therapy literature applicable to the problems of musicians.

\section{Medical Literature}

Harman (1982) reviewed past literature relative to occupational diseases of instrumental musicians, and reported finding the mention of various health consequences for the professional musician. One national musician's union produced figures from 1959 - 1967 which showed a life expectancy 22 percent below the national average. However, statistical data for the prevalence of musculoskeletal or other systemic problems were lacking.

Since that time, several studies have been conducted to identify musician's problems and gain information on their prevalence. Caldron et al (1986) completed a survey with 250 high level non-wind instrumental performers who were asked about demographic data, playing experience, symptoms, injuries, and treatment rendered for injuries believed to be 
related to playing an instrument. Of this group, 59\% reported musicallyrelated musculoskeletal disorders. The most commonly reported diagnoses were tendonitis, muscle spasm, and nerve entrapment. Comments from the musicians led to the impression that many of them sought unofficial medical advice from colleagues or teachers to try unusual treatment methods, such as "practicing through the pain," using weighted objects on the extremities during practice, or isolating individual digits for practice by binding others. Environmental factors were frequently blamed for increasing muscular tension and back/neck pain, such as stage chairs of improper height and inadequate stage lighting. This group of physicians concluded that musculoskeletal ailments were relatively common, and at times were the source of significant disability measurable in loss of practice time, reduction in facility, and occasionally caused the premature curtailment of a career.

The response rate for Caldron's (1986) study was very low (30\%), in spite of assurances of confidentiality. It was suspected that many professionals declined to participate because they feared loss of job or benefits as a result of disclosure. Confidence in the accuracy of estimates of disease incidence is low with less than a nearly $100 \%$ response rate. This could explain why later studies showed higher levels of incidence.

The concept of overuse is well known in industrial medicine and sports medicine, and is relevant to the problems of performing artists as well. Overuse injury may be defined as "the damage that occurs when a tissue is stressed beyond its anatomic or physiologic limits, either acutely or chronically" (Lederman \& Calbrese, 1986, p. 7). Simply stated, if a 
part is flexed enough times, it begins to wear out. Lederman and Calbrese describe various forms of overuse syndrome. The type affecting the musculotendinous unit is most commonly noted by pain in the wrist, hand, or proximal forearm. Patients may report swelling or weakness, but rarely is there evidence of either. Other forms of overuse include syndromes originating from muscle pain, nerve entrapment, and occupational palsies, in which there is a problem with motor control. Limitations in strength, flexibility, or abnormal muscle tone may predispose a performer to injury, as well as changes in the way a musician holds the instrument, the force used to play, or how the practice schedule is arranged. "A history of uninterrupted and often intense playing is frequently obtained from individuals with musically related injuries" (Lederman \& Calbrese, 1986, p. 9).

The incidence of overuse syndrome was studied by Fry (1986a) through interview and examination of 485 orchestral players from various American and Australian symphonies. This survey evaluated the occurrence of overuse syndrome as reflected by pain experienced by the players, not including weakness or loss of control that can also occur from this disorder. Even with this narrow definition of overuse injury, Fry found the overall incidence to be $64 \%$ of all musicians interviewed. About $25 \%$ of these had experienced their symptoms longer than 5 years. Another impressive clinical finding was "the acceptance by many of the players that their condition of pain was a normal one. They had learned to live with it. The players tended to underestimate their problems or to conceal them" (Fry, 1986a, p. 53). 
In an article entitled "Doctor, It Hurts When I Play," two neurologists describe results of a study conducted on 108 musicians who presented with the chief complaint of playing-related pain (Newmark \& Hochberg, 1987). Players of keyboard instruments were most commonly afflicted (47.2\%), followed by bowed string instruments (19.4\%) and guitar (10.2\%). Pianists tended to have pain in their right hands and arms, reflecting the increased strength necessary to play thinner treble strings or the more demanding technique required for the right hand. Left hand problems were more prevalent among string players.

In half of the patients their symptoms resulted in loss of speed, volume, or control. Rapid passages requiring arpeggios, octaves, or trills were often most affected. All patients experienced increased symtoms while playing. Most had symptoms while performing daily chores. To accommodate symptoms, most patients decreased (48\%) or ceased (23\% of patients for 1 week or more) playing. Many (40\%) altered their playing technique $(14 \%)$, repertoire $(14 \%)$, fingering $(8 \%)$ or instrument $(4 \%)$, viewing pain as a challenge. Remarkably, 7 patients actually increased their schedules, assuming that pain resulted from insufficient practice (p. 94).

Newmark and Hochberg carried out therapy in two stages:

In the first stage inflammation was controlled with anti-inflammatory medications. The cardinal principle was to rest the afflicted limb; splinting sometimes proved necessary. In the second stage (usually within 2-3 weeks) the affected muscles, usually the interossei and lumbricals, required strengthening in a graded manner to avoid a recurrence of inflammation. 
The treatments of choice were physical therapy, non-resistive exercises such as swimming, and eventually a graded return to practice. One recommended method was to practice only 15 minutes per day to start, then 15 minutes two times per day, then three times and four times per day, and only then proceed to gradually longer practice sessions.

The most comprehensive study of musicians' problems to date, spearheaded by the International Conference of Symphony \& Opera Musicians (ICSOM), involved 2212 members of nationally recognized orchestras. One of the major purposes was to determine the prevalence of musculoskeletal and other medical problems. Each musician could list up to four problems in order of severity, and then list the treatments they had tried and how effective the treatments had been. The results of their survey showed a very high prevalence of medical problems: $82 \%$ of ICSOM musicians reported experiencing a medical problem, and $76 \%$ listed one problem as severe in terms of its effect on their performance. The shoulder, neck, and back were commonly reported sites of disorders. Problems of the left hand, fingers, and wrist reached 39\%, whereas problems of the right hand, fingers, and wrist totaled $28 \%$. Stage fright and eye strain were the most prevalent of the non-musculoskeletal problems reported. The percentage of musicians mentioning medical problems also differed by type of instrument. String players were hit hardest: $84 \%$ reported at least one problem; $78 \%$ indicated at least one severe medical problem (Fishbein, Middlestadt, Ottati, Straus, \& Ellis, 1988). 
In a subsequent study, Fishbein and Middlestadt (1989) further analyzed the prevalence of musculoskeletal problems among the string players who participated in the ICSOM survey. Their results provided strong evidence for statistically significant differences in the prevalence of severe problems as a function of musculoskeletal location, the string instrument the musician plays, and gender.

Fry (1986a) describes the unique hazards of each instrument group, which are summarized below:

Violin and Viola: These players play almost continuously in the orchestra; muscular overuse both from static loading and repetitive activity occurs frequently. Painful overuse injury of the hand and wrist is common in both the bowing hand (right) or the fingering hand (left). Painful extensor and flexor muscle groups are likewise common in the forearms, with triceps and biceps lesions being less common. Aching in the neck and left shoulder muscle groups, which are used to hold up the violin, is common and becomes more frequent and severe as the players become older. Pain in the right shoulder with tenderness in the rotator cuff is common also, and such lesions have ended the careers of many famous violinists. The development of premature degenerative cervical spine disease has been associated with long hours of holding the violin between the chin and the left shoulder.

Cello Cellists are subject to the same types of upper limb disorders as violinists, although the degree of abduction of the right shoulder and the speed of playing is usually less, so the lesions may be correspondingly less severe. Cellists, however, frequently report pain in the lumbar spine area 
associated with long periods of sitting with restricted movement. Seating for the cello section is critical, as are periods of rest from this sitting position.

Double Bass This instrument is larger than the player, and takes a great deal of strength to play. Backache is almost the rule in the early stages of playing this instrument. However, a response to spinal exercise and muscle building programs may keep the player comfortable. Both upper limbs may become affected with overuse, although in general, the problem is less frequent and less severe than with cellists or violinists.

Clarinet and Oboe Supporting the instruments affects first and most profoundly the web space muscles, which must remain in sustained constraction to retain the relationship between the instrument and the fingers that carry out the keywork. In addition, the ligaments of the carpometacarpal joint at the base of the thumb suffer highly geared leverage. Fry recommends the use of posts to support the instrument to alleviate or prevent these probiems.

Bassoon This instrument weighs between 6 and 9 pounds. If played in a standing position, the weight is transmitted entirely to the spine. In the orchestra it is played in a seated position, with the seat strap partially supporting the instrument. The tilt of the instrument must still be corrected by the hands. The static loading is thus considerably reduced but not eliminated. Because of its weight, the safest way to play the bassoon is in the seated position with the bassoon supported from a spike on the floor. The playing hours that cause risk of overuse are during practice more than from orchestral performance, which is sporadic. 
Flute The flute is a lighter instrument and the weight is shared by both hands. It may weigh less than $\mathbf{4 0 0}$ grams, although some instruments are heavier. The right shoulder is in the abducted position, and this predisposes to overuse of the right shoulder muscles. Flutists may play the flute with a support and thus eliminate the static load of the flute but not of the right arm itself. All of these players are vulnerable to overuse anywhere in the upper limb and in the cervical, uppoer thoracic, and lumbar spines. The piccolo is a much smaller instrument, and requires more wrist extension to hold. Some players have developed carpal tunnel syndrome from this static position

Brass Section These players have to cope with heavy instruments, with the exception of the trumpet. The trombonist must hold the instrument up with the left arm, which the right moves to change the length of the tube. French horn players must hold most of the weight of the instrument with their left thumb, which becomes prone to injury. The weight of the brass instruments is transmitted to the spine through the arms. Fry states (1986a) that the matter of spinal loading in brass players is presently under investigation.

High pressure instruments that appear to produce special problems are the trumpet and oboe. The trumpet may produce near blackout on playing sustained high notes and, like the oboe, it may aggravate such conditions as hernias, hemorrhoids, or laryngoceles. Intraocular bleeds are not unknown with trumpet playing.

Percussion players suffer painful lesions from the neck and scapula area, and to the intrinsic muscles of the hands and associated joint 
ligaments. While using drumsticks, percussionists move their wrists in constant ulnar deviation, causing the ulnar nerve to be susceptible to neuropathy.

Guitarists must hold the left wrist in an flexed position, which may irritate the median nerve. Difficult right hand technique can also lead to overuse syndrome.

\section{Causes of Problems}

Brandfonbrener (1986a), a physician who has treated many musicians and is also editor of the journal Medical Problems of Performing Artists, attributes the high incidence of problems among musicians to the many stresses and strains of their occupation. They undergo years of arduous and intense training, after which they must face a job market with limitless competition and limited compensation. Only a few achieve stardom; most must hustle, holding multiple jobs and working long and irregular hours with frequent travel.

Musicians have traditionally been reluctant to seek help for their ailments, because of the threat to their employability if a disability becomes known (Brandfonbrener, 1986a). Recently, however, there has been more openness about medical problems, and in the last five years various multispecialty centers for performing artist have been established as a direct response to the increased demand.

Musicians tend to have a high acceptance of pain, as illustrated by a study conducted on the medical problems in secondary school-aged musicians (Lockwood, 1988). The 113 respondents, who played an 
average of 19 hours per week, had already attained a high level of musicianship. Seventy-nine percent believed that pain is acceptable in overcoming technical problems, but there was no difference in the prevalence of problems among those who subscribe to this belief compared to those who do not. The origin of this belief is likely to be complex, and may include elements of pain being a desired end-point, and possibly a feeling of invincibility that teenagers may possess.

\section{Prevention of Problems}

What is in the literature regarding the prevention of musculoskeletal disorders? Lockwood (1988) outlines several important tasks of music teachers that may lead to reductions in the prevalence of music-related problems: teaching students that pain is not an acceptable part of playing and possibly including instrument-specific hand conditioning programs in music pedagogy.

Dr. Fry suggests that overuse syndrome is preventable through the control of use and recommends that players use instrument supports when necessary to unburden their own muscles from static holding of the instrument. He illustrates various holding devices for clarinets, violins, and violas. The music teacher has enormous influence over students, and must encourage students to behave sensibly in the practice room. "It is the music teacher's task to help the student gain a well coordinated, energyefficient and seemingly effortless technique" (Fry, 1986b, p. 729).

Regarding practice habits, Fry states: "It is wise for the musician to limit practice segments to, say, 25 minutes and then take an arbitrary 5 
minute break. The musician will notice that the muscles are more responsive after the break, so the quality of the practice will be better" (p. 729). In adddition to safe practice habits and instrument supports, Fry recommends exercises promoting body awareness and control (eg, the Alexander and Feldenkrais techniques). "The musician should have sporting or physical activities to balance the hours of sedentary activity. Activities that extend the range of motion of the spine and strengthen the muscles that stabilise and move it should be encouraged. Repertoire that causes pain or persisting discomfort is best abandoned. These principles of prevention of overuse should be examinable material in the curriculum of tertiary music schools" (p. 729).

Spaulding (1988) discusses an innovative prevention program at the Trondelag Music Conservatory in Norway. The initial five-week course is obligatory for entering students; subsequent courses are elective. The major effort is to motivate and instruct students so that they can monitor their own practice and playing habits. Spaulding emphasizes the need for interdisciplinary effort between artists and health professionals. Families and early teachers are important allies of prevention. At the Trondelag Conservatory most students enter at about age 19. It is not uncommon that they bring with them considerable technical skill, a history of pain or periodic disability, and associated habits that may include the expectation and acceptance of pain as a part of playing. Spaulding observes that most of the younger students successfully manage to implement self-regulatory habit changes, allowing them to maintain pain-free playing. However, 
after the mid-twenties habits in instrument playing are significantly more difficult to affect with the introduction of new prevention techniques.

The Conservatory's initial course includes instruction in physiology and anatomy, postural balance, ergonomics of playing instruments, and relaxing. Students leam how to observe the school's "healthy use of the practice room" rules, and a sequential physical warm-up to be used prior to technical warm-up with their instrument. Detecting early signals of discomfort is a skill of paramount importance in avoiding musculoskeletal problems. Self-observation skills are reinforced by the keeping of a daily practice log, reporting to oneself about practice progress and goals, practice/sleep/nutrition patterns, effective use of time, resolution of personal problems, etc. Self care is emphasized, as is the use of a "quiet time," for structured mental and physical pauses in a busy schedule. Establishing the habit of actively seeking comfort and resilience in living and playing broadens the musician's coping capacity in the health continuum (Spaulding, 1988).

\section{Psycholegical Disorders}

In addition to the physical symptoms, there is the range of psychological problems such as performance anxiety and depression, despair about careers, and marital problems. The stress of the job can foster drug or alcohol abuse. Articles regarding the incidence of psychological disorders are more rare than those describing physical disorders, but medical practitioners from the past have agreed that emotional factors aggravate the physical symptoms (Fry, 1986b). 
In his study of the prevalence of overuse syndrome in Australian music schools, Fry reported a direct correlation between the onset of symptoms and increase in the time spent in practice multiplied by intensity of music practice. The surge in practice time was brought about by a competition, a recital, the study of a new work, or a change of teacher. All of the students with physical symptoms also showed some psychological disturbances, especially a high level of anxiety. They expressed their concern about their future and about the possibility of not being able to continue studying music. Over half of the students with overuse injury had been told by either a doctor or by friends that there was nothing really wrong and that it was in the mind. These students expressed a much higher grade of anxiety and a loss of self-esteem. Fry also reported the common occurrence of depression along with overuse syndrome. He postulated that the activity of playing music in itself could be mood-elevating, as jogging as been shown to be (Martinsen, Medhus \& Sandvik, 1985). Perhaps the brain without its accustomed dose of enkephalins is predisposed to depression. This association needs further investigation (Fry, 1987).

Among ICSOM musicians, stage fright was listed as the most common non-musculoskeletal problem; $24 \%$ reported it as a problem, $16 \%$ reported it as a severe problem (Fishbein, et al, 1988). Stage fright is experienced in a variety of ways, including nausea, dry mouth, memory lapses, muscular weakness, tremors, or hyperventilation. All of these can be not only personally unpleasant but musically disastrous. Some physicians report good success with beta blockers to curb performance anxiety, although they worry that too many players use the drug without 
medical supervision. Beta blockers may produce side effects including bradycardia, muscle fatigue, insomnia, and depression. Therefore, unsupervised use can be risky (Lehrer, Rosen, Kostis, \& Greenfield, 1987). "When stage fright becomes so pervasive that it crops up during rehearsals and every time the person begins to play, other factors are at work that should be treated with counseling" (Hamilton, 1987, p. 20).

At a conference entitled "Playing Hurt" Pruett (1986) of the Yale Child Study Center discussed performance anxiety. Anxiety is a motivational force and is not itself pathological. Performance anxiety is similar to other types of anxiety, and can worsen under the following circumstances:

- when performance is too closely tied to self-esteem

- when a perfect performance (not making music) is the goal

- in front of highly critical judges or artistic experts

- with more difficult musical material, especially by memory

- if the musician feeis unprepared

- in intense competition for few places.

Pruett noted that beta blockers do not eliminate anxiety, but merely inhibit certain physical manifestations of it. To cope with the psychological element of anxiety, he suggests musicians accept that performance anxiety is part of the performing process. They should prepare the body and mind for an unusual event by developing small, calming rituals using relaxation techniques and de-sensitization. He recommends that stress be addressed throughout a musician's life, not only in a crisis. One of the worst stress factors is "loneliness in the group." As a means of coping with stress, 
Pruett emphasized the need for involvement in other interests with time off from music.

\section{Occupational Therapy Literature}

Revak (1989) published an article in the American Journal of Qccupational Therapy a study which investigated the incidence of upper extremity discomfort among piano students. Out of 71 respondents, 30 (42\%) indicated they had experienced physical discomfort in their hands or arms that persisted or recurred for more than one week, and that impaired their ability to practice the piano. Revak observed that piano students who experienced discomforts such as fatigue, weakness, and muscle cramp often did not seek treatment. "Students may have perceived certain discomforts as less threatening to their physical well-being or may have believed that a certain level of discomfort was an inevitable part of becoming an accomplished musician" (p. 152). Revak believes that occupational therapists can assume an important role in screening musicians who seek medical treatment by focusing on areas such as upper extremity function, practice habits, work and leisure activities, stress factors, and coping mechanisms.

Goodman and Staz (1989) conducted a survey on the effectiveness of occupational therapy for musicians with upper extremity overuse syndrome. Twenty-six musicians responded who were seen by an occupational therapist at the Medical Center for Performing Artists at the Cleveland Clinic Foundation from 1984 to 1987 . The musicians were asked to rate their pain levels before and after therapy during periods of 
rest, while playing, after playing, and during activity. Therapy methods included use of ice and heat; exercise and activity programs to increase strength, flexibility, endurance, dexterity, and coordination; adaptation of the instrument, playing position, or performance chair; adaptation of the practice and performance schedule; relaxation techniques; and instruction in body mechanics. Sixty-five percent of the musicians reported that the therapy was effective at decreasing symptoms and increasing work productivity. Ninety-four percent of patients seen since 1986 reported that the therapy was effective. This was a very useful study; however, the variability in initial pain levels, the lack of a control group, and the subjective nature of the pain scale make it problematic to draw strong conclusions from these data.

Dezell (1987) recently conducted a study of 208 orchestra players, for the purpose of examining the correlation between their occupationally related physical and psychological disabilities and their occupational role dysfunction (see definition). These factors were shown to co-exist in the sample selected; however, no significant correlation could be found, which the author contributed to lack of diversity in the sample. Of the 208 musicians who participated in this study, only 12 did not report experiencing physicial or psychological disabilities related to their occupation. The existence of occupational role dysfunction was evident through the high ratings of the acceptance of suffering and the degree of pushing oneself to one's physical and psychological limits. Also, the questionnaire did not include a way in which the musicians could indicate 
the severity of their problems. Without this indication, their disabilities may have been over-represented.

In her section on "Implications for Further Research," Dezell suggested that a similar study be conducted with two specific groups, one including participants who experience physical and psychological disabilities, and another group including only those who do not experience physicial or psychological disabilities related to their profession. The existence of role dysfunction would be examined for both groups. This study has endeavored to test more accurately for a correlation between the factors mentioned above.

\section{Qccupational Behavior}

In view of the high number of problems experienced by musicians along with the tendency to "ignore the problem and it will go away," questions are raised regarding the values and internalized expectations of this population. Perhaps pain and sacrifice are considered to be an accepted part of a musician's life. Perhaps their habits of many hours of practice per day, learned in their youth, lock them into a pattern of workaholism, leaving insufficient time for leisure, rest, or self-care activities. If their problems are viewed as insuffiencies in how they function in their role as musicians, then occupational therapy offers an excellent frame of reference for further investigation and treatment using the Model of Human Occupation (Kielhofner, 1985).

According to Kielhofner, occupational behavior is motivated, organized, and performed via three subsystems: volition, habituation, and 
performance. Volition is the energizing and motivating force, and is responsible for choosing and initiating behavior through personal causation, values and interests. Habituation is the middle level subsystem by which occupational behavior is organized via one's roles and habits. The performance subsystem is comprised of skills, by which one interacts with objects, events, or people, and is able to perform desired behavior. The Model of Human Occupation stresses the belief in internal control versus external control, and in the the individual's ability to respond to environmental stresses by developing adaptive skills and altering behavior in order to meet the demands of one's occupational role.

Occupational function and dysfunction are on a continuum, comprising adaptive versus nonadaptive berhaviors. Achievement, competence, and exploration represent levels of occupational function; inefficacy, incompetence, and helplessness are levels of occupational dysfunction. Sources of inefficacy may be environmental constraints, disease processes, or imbalanced lifestyles.

Using the above model, the musicians' values and perceptions would be examined in relation to their actions and behaviors, in addition to the objective observations of their physiological and psychological symptomatology. Occupational therapy therefore would not only assist in the healing process of physiological injuries, but would support injured musicians in developing adaptive skills and habits in order to more adequately meet the demands of their occupation. 


\section{CHAPTER 3}

\section{DESIGN AND METHODOLOGY}

\section{Objectives}

The objectives for this study were to:

1. Determine whether a significant correlation exists between selected habits and values of professional musicians and the presence of reported work-related physical and psychlogical problems.

2. Determine whether a significant correlation exists between the musicians' values regarding effort and sacrifice and their playingrelated habits.

3. Propose recommendations for treating injured musicians, using the .Model of Human Occupation.

\section{Questions}

The research questions generated for this study were:

1. Is there a significant correlation among specific factors relative to the habits of professional musicians and an increase in physical or psychological dysfunction?

2. Is there a significant correlation between values regarding effort and sacrifice and the level of physical or psychological dysfunction among professional musicians? 
3. Is there a significant correlation between the collective values of professional musicians regarding effort and sacrifice and practicerelated habits?

\section{Null Hypotheses}

The null hypotheses tested in this study were :

1. There will be no significant correlation between an increase in occupationally-related physical or psychological dysfunction in professional musicians and:

a) an increase in practice time without taking a break

b) an increase in the number of hours spent playing one's instrument in an average day

c) a decrease in exercise

d) a decrease in leisure/socialization time

e) a decrease in the time spent sleeping

2. There will be no significant correlation between an increase in occupationally-related physical or psychological dysfunction in professional musicians and:

a) an increase in how much a musician allowed playing to interfere with meeting personal and social needs

b) an increase in how much pain was considered normal to master an instrument

c) an increase in how much personal time was sacrificed to accommodate a performance or competition 
d) an increase of pushing to one's physical and psychological limits

3. There will be no significant relationship between the collective values of professional musicians regarding effort and sacrifice and the following practice-related habits:

a) time spent in individual practice

b) practicing longer sessions without taking a break

c) hours spent in playing-related work

\section{Sample and Procedures}

The subjects for this study were musicians who were members of the following professional orchestras: the Billings Symphony, the Pacific Symphony, the San Jose Symphony, and the Spokane Symphony. The following university orchestras were also surveyed: the San Jose State University Symphony, the San Francisco State University Symphony, and the Occidental College Orchestra. These orchestras were selected by convenience of location, or by familiarity with the conductor or players of that orchestra. It was hoped to obtain a sample which represented the range of ages of performing musicians, and also the range of their professional development. One criterion for selection was a minimum practice time of three hours per week, or at least one hour per day of playing time (performance time included). This indicated the pursuit of music as a primary or secondary vocation, paid or unpaid.

A questionnaire was developed by the researcher to include information on demographics, use of time throughout an average day, 
practice habits, values or internalized role perceptions regarding pain and personal sacrifice, and information on the physical and psychological symptoms experienced (see Appendix A). The questions on demographics were similar to those used by Dezell (1987). Question 3, which asked the musicians to describe their primary role, was added in order to gain information on the mixture of respondents. The questions regarding practice and daily use of time were rephrased for more clarity. Question 7 on the use of time in an average day was expanded to give separate categories for exercise, sleeping, meal preparation/eating, and hygiene/ grooming/dressing. Question 8 was added to give another measure of sacrifice to meet playing demands, and also to give a measure of the balance of roles in the musicians' lives. An additional response was added to Question 9. The question regarding pain considered normal (Question 10) was left unchanged. Question 11 was rephrased for better definition from "how much personal sacrifice do you make to accommodate practice time" to "what percentage of personal time is lost to accommodate practice time." Question 12 was left unchanged. Questions 13 and 14 were adapted to allow the musicians to indicate not only the presence of a symptom (as in Dezell's study), but also the severity and duration of the problem. The timeframe of when these symptoms occurred was more defined, with the parameter of six months prior to filling in the questionnaire. With these changes it was hoped to gain a more realistic measure of the musicians' problems as they affected their performance. The questions in Dezell's study regarding the relief of the symptoms were omitted from this study. 
The questionnaires were distributed during rehearsals of the above orchestras, by either the researcher or a spokesperson who read an introduction as to the purpose of the study. An informed consent letter was attached to each questionnaire (see Appendix B), along with a stamped, self-addressed envelope. Some participants returned their questionnaires in person during the rehearsal, but most retumed them by mail. Approval for this study was granted by the Committee for the Protection of Human Subjects, San Jose State University, and was also obtained by the conductor and personnel manager for each orchestra. 


\section{CHAPTER 4}

\section{DATA AND RESULTS}

\section{Data Analysis Procedures}

Of approximately 500 questionnaires distributed, a total of 208 questionnaires were returned, yielding a response rate of 42 percent. The respondents were screened to include only those who played their instrument at least one hour per day (performance time included), or who practiced individually at least 3 hours per week. Forty-four returned questionnaires were eliminated due to incompleteness or insufficient time in practice, resulting in 166 usable questionnaires.

Descriptive statistics were used to analyze the frequency, mean, and standard deviation of the appropriate questions. Three factors were individually calculated. The "physical dysfunction index" was computed by multiplying the number of weeks a reported symptom occurred by the percentage of time lost from playing. The "psychological dysfunction index" was computed in a similar manner. A measure of aggregate values regarding perceived effort/sacrifice was calculated by adding the responses of questions $8,10,11$, and 12 , then dividing by four.

The correlational statistical analyses were computed using an IBM P.C. with the Statistical Package for Social Sciences (SPSS). Pearson correlations were calculated for Question 7 relative to the level of physical/psychological dysfunction. The Kruskal-Wallis non-parametric 
test was calculated for each separate question $6,8,10,11$, and 12 relative to the physical and psychological dysfunction indexes. Pearson correlations were then used to compare the average value factor with physical and psychological dysfunction (average of questions $8,10,11$, and 12 relative to questions 13 and 14).

\section{Descriptive Data}

Of 166 participants, 83 were male and, coincidentally, 83 were female. The ages of the participants ranged from 17 to 73 , with a mean of 34.7, and a standard deviation of 12.6.

Table 1 delineates the primary roles of the musicians, with the majority describing themselves as professional players. The three conductors were also instrumentalists.

Table 2 shows the distribution of instruments played. The largest category is string players, at 54 percent. This distribution is representative of the percentages of a typical symphony.

The number of hours per week spent in individual practice is shown in Table 3, with a range from 3 to 40 hours, a mean of 10.81 , and a standard deviation of 7.34 .

Table 4 depicts the distribution of responses to the Question 6: "How long do you usually practice at one time before taking a break?" About half of the respondents indicated that they practiced between a half hour to an hour before taking a break, and nearly a fourth responded they would practice from an hour to an hour and a half at each session. 
TABLE 1

Primary Role as a Musician $(0,3)$

$\underline{\mathrm{n}}=166$

Primary Role

Frequency* Percentage

Student

39

20.9

Professional Player

104

55.9

Teacher

24

13.9

Amateur Performer

16

8.7

Conductor

\begin{tabular}{cc}
3 & 1.6 \\
\hline 186 & 100.0
\end{tabular}

* 17 had multiple responses 
TABLE 2

Primary Instrument Played (Q. 4)

$\underline{\mathrm{n}}=166$

\begin{tabular}{lcc}
\hline Instrument & Frequency* & Percentage \\
\hline Strings & 94 & 54.4 \\
Woodwinds & 27 & 15.6 \\
Brass & 38 & 22.0 \\
Percussion & 6 & 3.5 \\
Keyboard & 7 & 4.0 \\
Harp & 1 & .5 \\
\hline
\end{tabular}

*7 had multiple responses 


\section{TABLE 3}

Hours per Week Spent in Individual Practice $(0.5)$

$$
\underline{n}=166
$$

\begin{tabular}{lcc}
\hline Hours & Frequency & Percentage \\
\hline $0-5$ & 39 & 23.49 \\
$6-10$ & 63 & 37.95 \\
$11-15$ & 31 & 18.67 \\
$16-20$ & 20 & 12.05 \\
$21-25$ & 5 & 3.01 \\
$26-30$ & 4 & 2.41 \\
$31-35$ & 2 & 1.20 \\
$36-40$ & 2 & 1.20 \\
Total & 166 & 100.00 \\
\hline
\end{tabular}

Mean $=10.81$

Standard Deviation $=7.34$ 
TABLE 4

Time Spent Practicing Before a Break (Q . 6)

$\underline{\mathrm{n}}=166$

Hours

Frequency Percentage

a) 0.0 to .5

19

11.45

b) 0.6 to 1.0

85

51.20

c) 1.1 to 1.5

41

24.70

d) 1.6 to 2.0

15

9.04

e) 2.1 to 3.0

4

2.41

f) 3.1 and up

0

0.00

$b+c$

1

0.60

no response

1

0.60

Total

166

100.00 
Table 5 presents the participants' use of time in an average day. An average of 3.93 hours were spent in playing related work, and an average of 6.11 hours were spent in other types of work. Meal preparation and eating required 1.97 hours; hygiene, grooming, and dressing averaged 1.07 hours. The average time spent in exercise was .83 hours per day; leisure and socialization averaged 2.57 hours, and the average number of hours spent sleeping was 7.43 .

Table 6 shows the distribution of responses to Question 8: "To what extent does the time spent playing your instrument interfere with meeting your personal and social needs?" On a scale of one to five (one indicating no interference and 5 indicating a great deal of interference, the mean score was 2.74 with a standard deviation of 1.16 . One musician in his early twenties added this comment: "Let's just say it's torpedoed most of my relationships!"

Table 7 depicts the musicians' responses to pain or weakness while playing, given five responses (see Question 9). The largest group, 77 musicians, indicated that they would decrease time spent in practice or take more frequent breaks. The next largest group (39 respondents) indicated that they would continue practice, and hope that the pain or weakness would subside. Seven musicians responded that they would increase practice time and content difficulty to overcome the pain or weakness.

Table 8 shows the responses to the Question 10: "How much physical pain do you consider normal in gaining mastery of an instrument?" On a scale of one to five, with one as no pain and five as 


\section{TABLE 5}

Use of Time (0.7)

$\underline{\mathrm{n}}=166$

Average Daily Hours

Mean

S.D.

a) Playing related work

3.93

2.19

b) Other work

6.11

2.65

c) Meal preparation/eating

1.97

.85

d) Hygiene/grooming/dressing

1.07

.50

e) Exercise

.83

.67

f) Leisure/socialization

2.57

1.63

g) Sleeping

7.43

.87 
TABLE 6

Interference With Personal and Social Needs (Q . 8)

$\underline{n}=166$

\begin{tabular}{lccc}
\hline $\begin{array}{l}\text { Amount of } \\
\text { Interference }\end{array}$ & Value & Frequency & Percentage \\
\hline No interference & 1 & 31 & 18.67 \\
& 2 & 32 & 19.28 \\
Some interference & 3 & 66 & 39.76 \\
& 4 & 23 & 13.86 \\
A great deai & 5 & 14 & 8.43 \\
& & $\overline{166}$ & 100.00 \\
\hline
\end{tabular}

Mean $=2.74$

Standard Deviation $=1.16$ 


\section{TABLE 7}

Response to Pain/Weakness While Playing (Q. 9)

$\underline{\mathrm{n}}=166$

Response

Frequency

Percentage

No response

23

13.5

a) Increase practice time and

7

4.1 content difficulty

b) Continue, and hope that it

39

22.9 will subside

c) Decrease time spent in practice,

77

45.3 or take more frequent breaks

d) Discontinue practice until

10

5.8 symtoms disappear

e) Seek help from a health professional

$\begin{array}{ll}14 & 8.2 \\ 170^{*} & 100.0\end{array}$

* There were 4 multiple responses 


\section{TABLE 8}

Physical Pain Considered "Normal" in Gaining Mastery of an Instrument $(Q, 10)$

$$
\underline{\mathrm{n}}=166
$$

\begin{tabular}{lccc} 
Amount of Pain & Value & Frequency & Percentage \\
\hline No pain & 1 & 40 & 24.10 \\
A little & 2 & 54 & 32.53 \\
Average & 3 & 56 & 33.73 \\
A lot & 4 & 15 & 9.04 \\
Intense & 5 & 1 & 0.60 \\
& & $\overline{166}$ & $\overline{100.00}$
\end{tabular}

Mean Value $=2.29$

Standard Deviation $=.96$ 
intense pain, the mean value was 2.29 , indicating that a little pain was considered normal.

Table 9 depicts the amount of personal time that is lost to accommodate practice time prior to a performance (see Question 11). Values one to five represented percentages of personal time lost. The mean was 3.27 , indicating a loss of $40-60 \%$ of personal time.

Table 10 indicates the amount the musicians felt they should push themselves to their physical/psychological limits in order to remain competitive (Question 12). Again, on a one to five scale, with one representing "not pushing" and five representing "pushing to the limits," the mean value was 3.25 , indicating that some pushing was considered necessary.

Table 11 shows the frequencies and percentages of the reported physical symptoms experienced in the last six months preceeding the time of filling in the questionnaire. The symptoms receiving the most responses were shoulder pain (45\%), back pain (45\%), and neck pain (43\%). Thirteen participants reported no physical symptoms. There were many multiple responses.

The physical dysfunction index (see Question 13 of Appendix A) was calculated by multiplying the duration of the symptom (measured in weeks) by severity of that symptom (percentage of time lost from playing). The scores ranged from 0 to 23.4. The mean physical dysfunction was 2.47 , with a standard deviation of 4.91 . The total number of respondents reporting physical symptoms was 153 (92\%). Close to half of this group (48\%), however, did not report any time lost from playing their 


\section{TABLE 9}

Amount of Personal Time Lost to Accommodate Practice Time Prior to a Concert/Audition/Competition (Q. I1)

\begin{tabular}{lccr}
$\underline{\mathrm{n}}=166$ & & & \\
\hline Percentage of Time & Value & Frequency & Percentag \\
\hline $0-20$ & 1 & 16 & 9.64 \\
$20-40$ & 2 & 32 & 19.28 \\
$40-60$ & 3 & 44 & 26.51 \\
$60-80$ & 4 & 38 & 22.89 \\
$80-100$ & 5 & 36 & 21.69 \\
\hline
\end{tabular}

Mean $=3.27$

Standard Deviation $=1.27$ 
TABLE 10

Amount Willing to Push to Physical/Psychological Limits (O. 12)

$\underline{\mathrm{n}}=166$

Amount of Push Value Frequency Percentage

Not push to limits

120

12.05

2

19

11.45

3

51

30.72

4

52

31.33

Push to limits

5

24

14.46

$\overline{166}$

$\overline{100.00}$

Mean $=3.25$

Standard Deviation $=1.19$ 


\section{TABLE 11}

Frequency of Reported Physical Symptoms * (O. 13)

$\underline{\mathrm{n}}=166$ (There were many multiple responses)

a) Headaches

b) Neck pain

c) Shoulder pain

d) Back pain

e) Pain in forearm/upper arm

f) Pain in wrist/hand/fingers

g) Tendonitis

h) Skin irritation

i) Tingling/numbness in extremities

j) Joint swelling/pain

k) Eye Strain

1) Ear problems

m) Other

No response
53

71

74

74

44

63

24

19

31

5

39

19

13

10
32

43

45

45

27

38

14

11

19

3

23

11

8

6

$*$ Total respondents claiming problems $=153(92 \%)$. 
instrument. This resulted in a majority (52\%) of respondents with a physical dysfunction level of zero. The large percentage of zero scores skewed the normal distribution of responses.

The reported psychological symptoms from Question 14 are shown in Table 12. The largest categories were restlessness (32\%), acute anxiety (27\%), and sleep disorders (24\%). Sixty-one respondents did not list any psychological symptoms, but others had multiple responses.

The psychological dysfunction index was computed by multiplying the duration of the symptom (measured in weeks) by severity of that symptom (percentage of time lost from playing). The mean psychological dysfunction index was 0.79 , with a standard deviation of 2.51 . This index ranged from 0 - 14.8. The total number of respondents claiming problems was $105(63 \%)$. However, 60 of the 105 respondents reported that no time was lost from playing. Their psychological dysfunction score was zero, in spite of the presence of symptoms. This resulted in a large group of respondents $(73 \%)$ who had a psychological dysfunction index of zero. Here again, the large percentage of zero scores skewed the normal distribution of responses.

Table 13 shows the frequency and percentage of reported stage fright related symptoms. Sixty-three percent of the respondents reported symptoms of stage fright. Fifty-five percent of the sample surveyed reported experiencing shakiness or incoordination while performing, and $30 \%$ reported experiencing memory lapses. The participants also reported 


\section{TABLE 12}

Frequency of Reported Psychological Symptoms* (Q 14)

$\underline{\mathrm{n}}=166$

Psychological Symptoms

Frequency Percentage
a) Restlessness
53
32
b) Sleep disorders
40
24
c) Stomach disorders
26
16
d) Eating disturbances
14
e) Acute anxiety
44
27
f) Depression
37
22
g) Use of drugs/alcohol
10
6
h) Other
8
5
No response
64
39

Total number of respondents claiming problems $=105(63 \%)$

* There were many multiple responses 


\section{TABLE 13}

Frequency of Reported Stage Fright Reiated Symptoms* (Q 15)

$\underline{\mathbf{n}}=166$

a) Shakiness/incoordination

92

55

b) Difficulty in swallowing

12

7

c) Muscle weakness

19

11

d) Memory lapses

50

30

e) Other: loss of concentration

11

7

f) Other: miscellaneous

23

14

No response

46

28

Total respondents claiming symptoms: 105 (63\%)

*There were many multiple responses. 
the percentage of accuracy lost while performing; the mean accuracy lost for all 166 respondents was $19.8 \%$.

Table 14 depicts the results of Question 16 on the Questionnaire, "How threatening are the previously mentioned symptoms to your career as a musician?" On the scale from one to five with one as "very little worry," and 5 as "a lot of worry," the mean value for all 166 respondents was 2.53 , indicating an average amount of worry was experienced.

\section{Correlational Data}

The data from Question 6 (practice time before taking a break) was analyzed in relation to the physical dysfunction index (from Question 13) as well as to the psychological dysfunction index (from Question 14). Pearson correlations revealed p-values of .86 and .41 , respectively, which did not indicate a significant correlation. However, it was evident that an increase in time spent practicing before taking a break had a positive relationship with an increase in physical and psychological dysfunction. The range of physical dysfunction nearly doubled with practice times greater than one half hour. The range of psychological dysfunction increased five times with practice times greater than one half hour. Figure 1 illustrates this relationship which is evident in the first three groupings of "hours before a break."

In Question 7 of the questionnaire, the respondents estimated their use of time in an average day. Pearson correlations were calculated for the use of time variables relative to physical and psychological dysfuntion. Table 15 shows which of these correlations had statistical significance. As 
TABLE 14

Reported Threat to Career (Anxiety regarding symptoms)

$\underline{\mathrm{n}}=166$

\begin{tabular}{lccc} 
Amount of Worry & Value & Frequency & Percentage \\
\hline No response & 1 & 3 & 1.81 \\
No worry & 2 & 51 & 30.72 \\
A little worry & 3 & 44 & 17.47 \\
Average & 4 & 23 & 26.51 \\
More than average & 5 & 16 & 13.86 \\
A lot & & $\overline{166}$ & $\overline{100.00}$ \\
\end{tabular}

Mean $=2.53$

Standard deviation $=1.32$ 
Figure 1. Physical/psychological dysfunction relative to the length of practice time before a break.

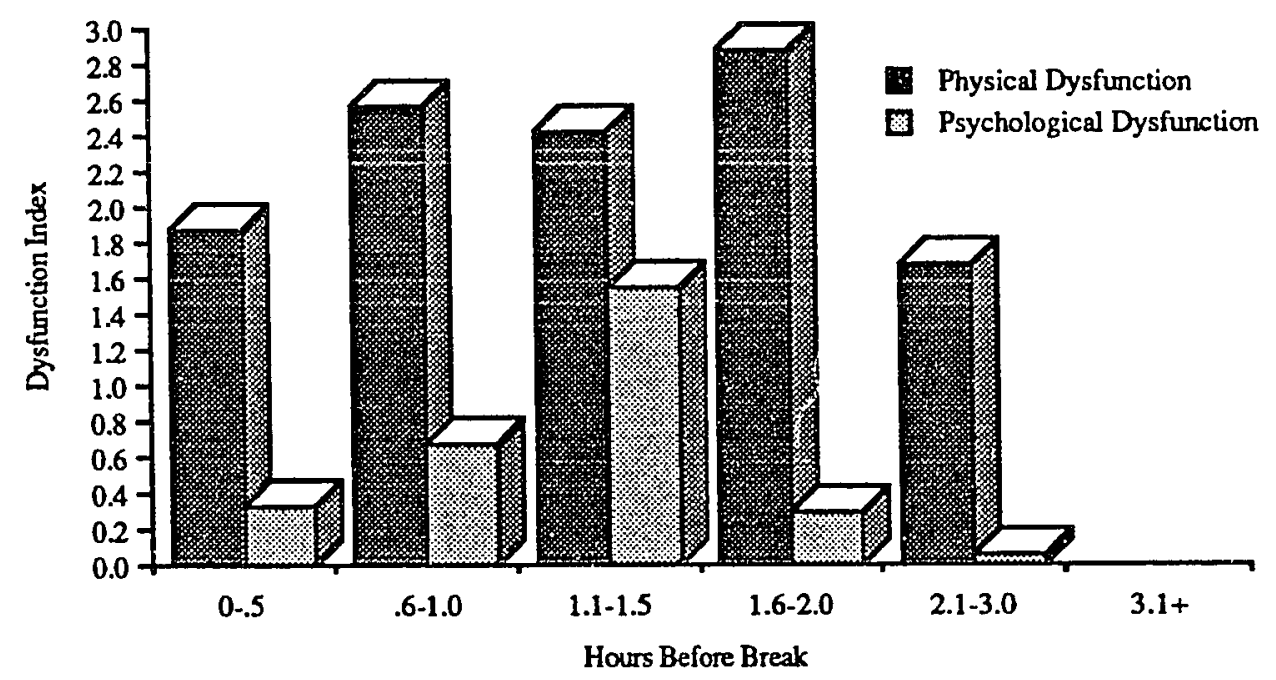

$\underline{\mathrm{n}}=(19)$

(85)

(41)

(15)

(4)

(0) 


\section{TABLE 15}

Use of Time in an Average Day Relative to Physical and Psychological Dysfunction

$\underline{n}=166$

\begin{tabular}{lcccc} 
Time Variable & \multicolumn{2}{c}{ Physical Dysfunction } & \multicolumn{2}{c}{ Psychological Dysfunction } \\
& Correlation & P-Value & Correlation & P-Value \\
\hline Playing related work & -.003 & .487 & .194 & $.006 *$ \\
Other work & .051 & .357 & -.088 & .129 \\
Eating/meal prep & .017 & .441 & -.001 & .494 \\
Hygiene/grooming & .128 & $.050 *$ & .111 & .077 \\
Exercise & .029 & .356 & -.052 & .252 \\
Leisure/socialization & -.179 & $.011 *$ & -.095 & .113 \\
Sleeping & -.014 & .431 & -.195 & $.006 *$ \\
& & & & \\
\hline
\end{tabular}

* Signifance is .05 or less 
time spent playing one's instrument increased, there was a significant positive correlation to an increase in psychological problems. A significant correlation was discovered which was not included in the hypotheses: as time spent in hygiene and grooming increased, so did the level of physical dysfunction.

There was no significant correlation between time spent exercising and physical or psychological dysfunction. As time spent in leisure and socialization decreased, there was a significant correlation to an increase in physical dysfunction (see Figure 2). With a decrease in time spent sleeping, there was a corresponding increase in psychological dysfuction. It was also observed that as time spent playing the instrument increased, there was a significant correlation to a decrease in time spent in nonplaying related work, eating, leisure, and sleeping.

The Kruskal-Wallis non-parametric tests were calculated for Questions 8, 10,11, and 12 relative to the physical and psychological indexes (Questions 13 and 14). The significance factors are reported in Table 16. For Question 8, which addressed how much interference was experienced with meeting personal and social needs, the correlation was not significant for physical or psychological dysfunction. However, as with Question 6, there was a greater variety of ranges with higher responses on the Likert Scale. Those answering "no interference" had a range from 0 2.1 , whereas the groups above this had dysfunction ranges at four to five times greater. This shows a positive relationship, which can be observed in Figure 3. 
Figure 2. Physical/psychological dysfunction relative to the hours spent per day in leisure or socialization.

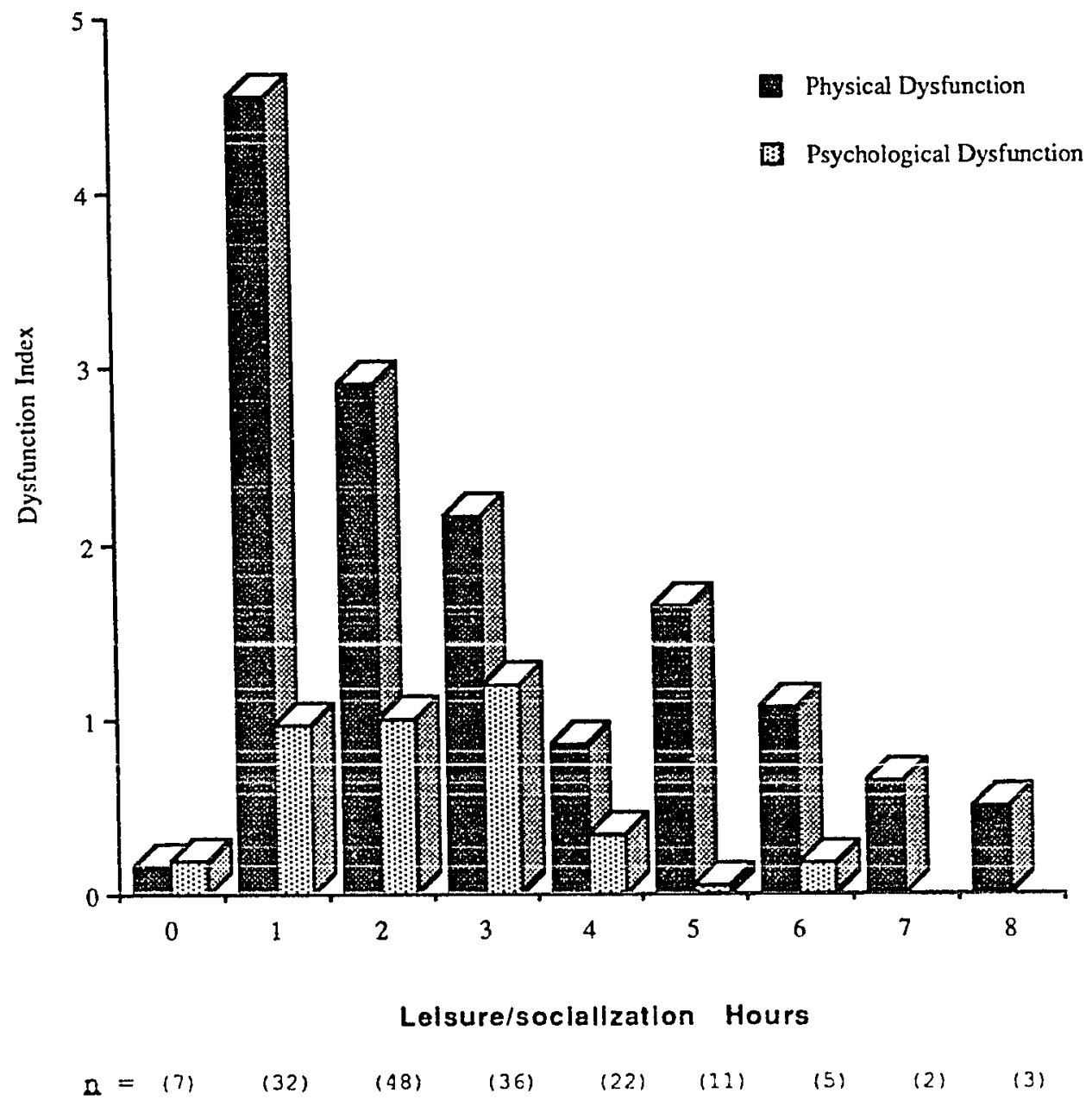




\section{TABLE 16}

Correlation Measures for Values Relative to Physical and Psychological Dysfunction

$\underline{\mathrm{n}}=166$

\begin{tabular}{|c|c|c|}
\hline Value & $\begin{array}{c}\text { Physical } \\
\text { Dysfunction } \\
\text { Significance }\end{array}$ & $\begin{array}{l}\text { Psychological } \\
\text { Dysfunction } \\
\text { Significance }\end{array}$ \\
\hline
\end{tabular}

Interference with personal $\quad .376$

.455 and social needs (Q. 8)

Pain considered normal

(Q. 10)

.241

$.005 *$

Personal time sacrified

.498

.407

(Q. 11)

Pushing to one's limits

(Q. 12)

.400

$.025 *$

Combined values

(Q. 8, 10, 11, 12)

$.005 *$

$.018 *$

* Significance of P-value is .05 or less. 
Figure 3. Physical/psychological dysfunction relative to interference with personal/social needs.

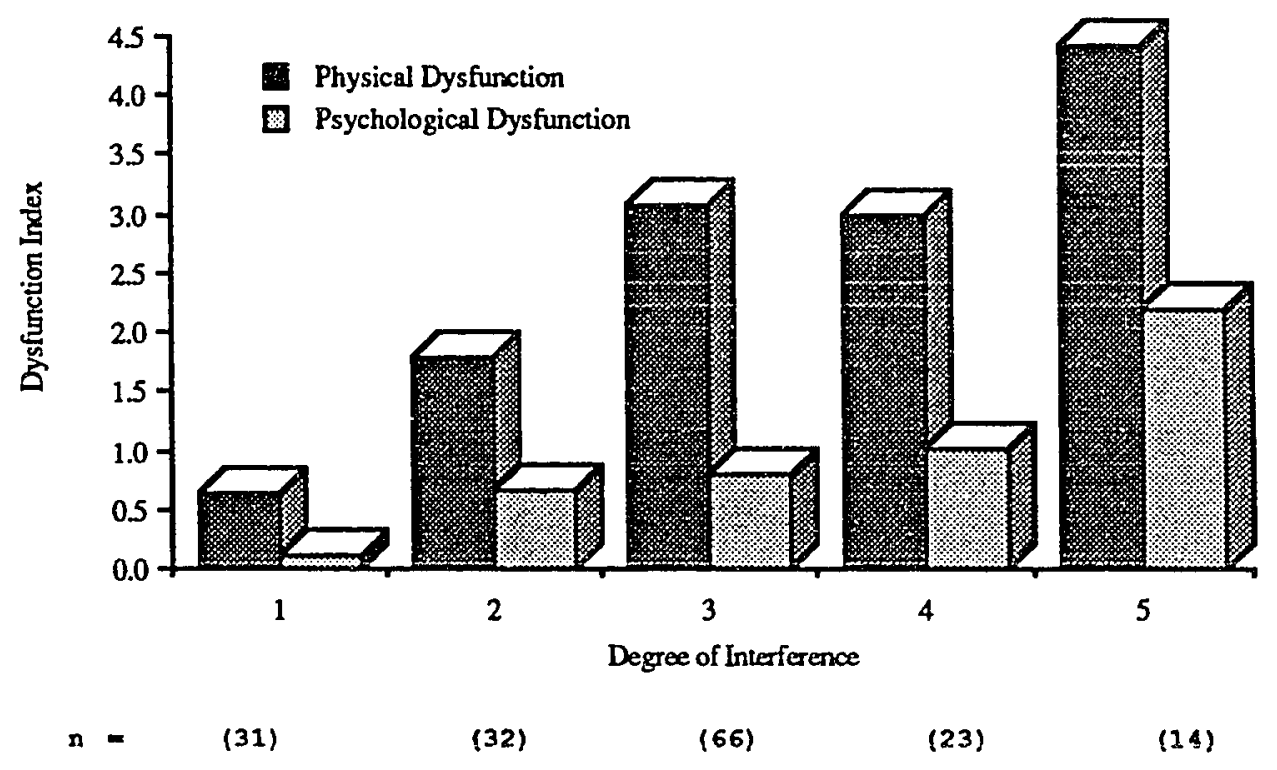


It was decided not to use Question 9 in the correlation analyses, since this question was not written as clearly as it should have been. It had been intended for the responses to show progressive dysfunction, but the inclusion of the word "weakness" muddled the issue. For example, if a violinist realized that his left fifth finger was fatiguing faster than the others, he might choose to increase practice time and content difficulty to overcome the weakness. This would not necessarily be a "dysfunctional" practice, but if the finger was causing pain, this response would be considered potentially damaging.

A significant correlation was found with the amount of pain considered normal to master an instrument and psychological dysfunction (Question 10). A general trend can also be viewed in Figure 4 of an increase in physical dysfunction with an increase in the acceptance of pain.

There was no significant relationship between the responses to Question 11 (what percentage of personal time is lost to accommodate practice time) and physical or psychological dysfunction. The lack of significance is probably due to the high number of reported zeroes for the severity of symptoms, which skewed the normal distribution of responses.

The value regarding the degree of pushing oneself to physical and psychological limits (Question 12) had a significant positive correlation to psychological dysfunction. A strong trend may also be seen in the relationship to physical dysfunction in Figure 5.

When the means of the four values regarding pain/sacrifice were considered collectively (the means of Questions 8,10,11, and 12 divided 
Figure 4. Physical/psychological dysfunction relative to the amount of pain considered normal to master an instrument.

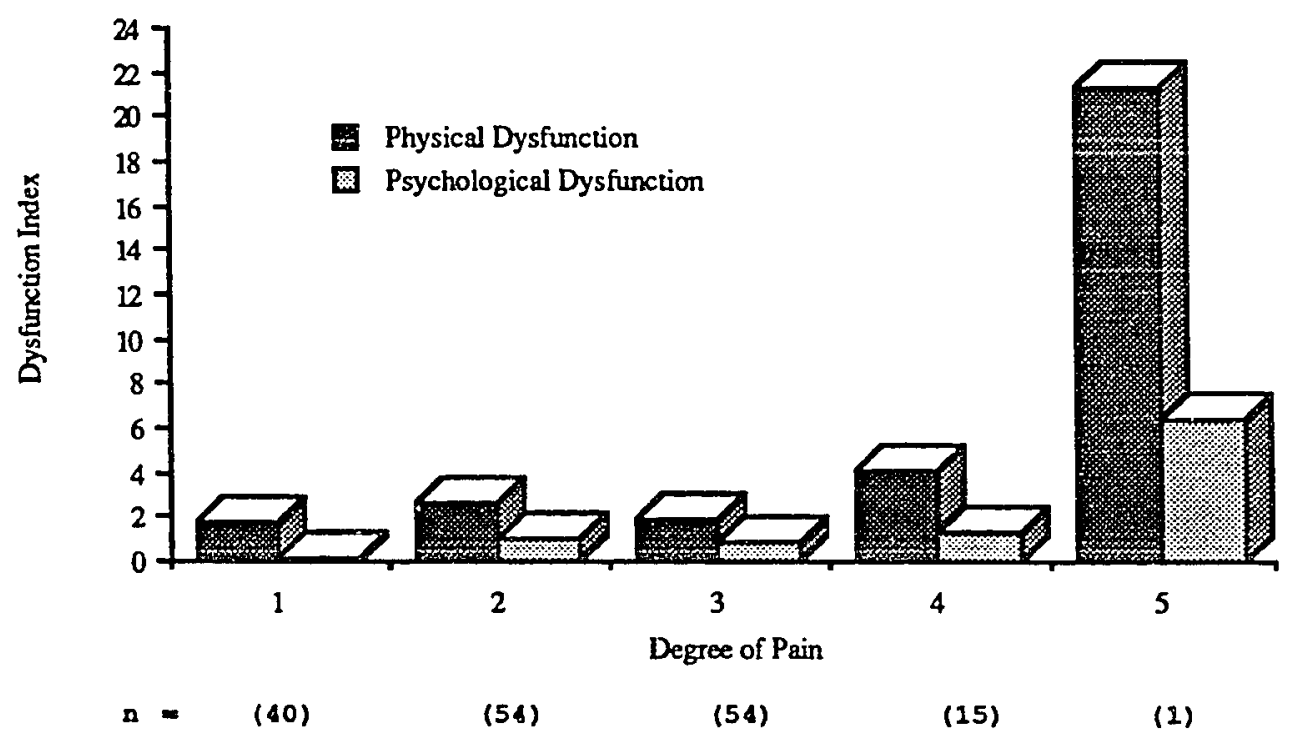


Figure 5. Physical/psychological dysfunction relative to the degree of pushing oneself to physical/psychological limits.

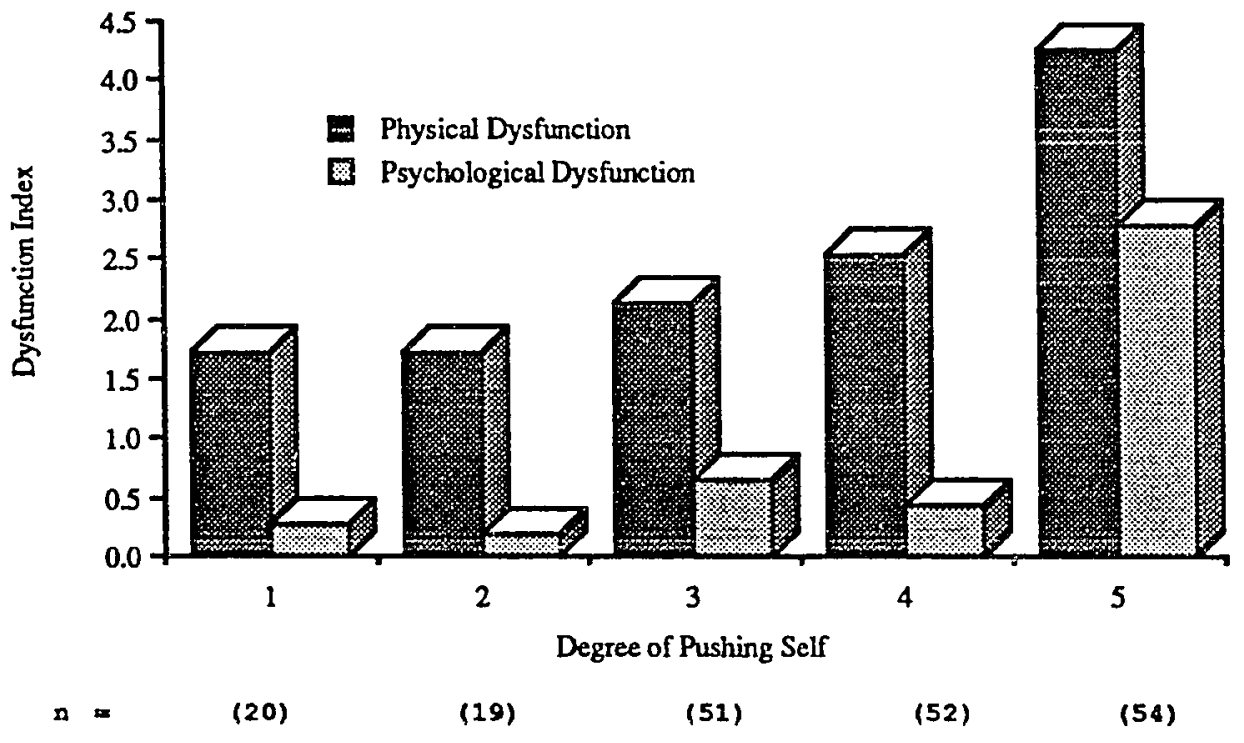


by four), they had a more normal distribution. The Pearson test showed significant correlations for both physical and psychological dysfunction, as seen in Table 16 under "combined values."

The combined values of pain/sacrifice were then correlated with three variables relating to the musicians' practice habits (Questions 5, 6, and 7a). Each of these correlations yielded significant results. Question 5, relating to the hours practiced individually per week, correlated with the mean of Questions 8, 10,11, and 12 with a p-value of .023. Question 6, which related to the length of practice session before taking a break, correlated with these values of pain/sacrifice with a p-value of .005. Question 7a, relating to the number of hours spent in playing-related work on an average day, correlated with the values of pain/sacrifice with a p-value of $<.001$, indicating a high level of significance.

\section{Results}

The first research question asked if there was a significant correlation among factors relative to the habits of professional musicians and an increase in physical or psychological dysfunction. The data from Questions 6 and 7 regarding the musicians' use of time and Questions 13 and 14 were analyzed for this question. The null hypothesis related to this question was stated: There will be no significant correlation between an increase in occupationally-related physical or psychological dysfunction in professional musicians and:

a) an increase in practice time without taking a break (Question 6). 
b) an increase in the number of hours spent playing one's instrument in an average day (Question 7a).

c) a decrease in exercise (Question 7e).

d) a decrease in leisure/socialization time (Question 7f).

e) a decrease in the time spent sleeping (Question 7g).

Significant correlations were obtained with a greater number of hours spent playing one's instrument in an average day, a decrease in leisure/socialization time, and a decrease in the time spent sleeping (see Table 15). Certain habits did not show a significant correlation to an increase in dysfunction. These were an increase in practice time without taking a break and a decrease in the time spent exercising.

The second research question asked if there was a significant correlation between values regarding effort and sacrifice and the level of physical or psychological dysfunction. The null hypothesis related to this question was: There will be no significant correlation between an increase in occupationalỉy-related physicai or psychological dysfunction in professional musicians and

a) an increase in interference with meeting personal and social needs (Question 8).

b) an increase in how much pain was considered normal to master an instrument (Question 10).

c) an increase in how much personal time was sacrificed to accommodate a performance or competition (Question 11).

d) an increase in pushing to one's physical or psychological limits (Question 12). 
The data from Questions 8, 10,11, and 12 were correlated with Questions 13 and 14 for this question., which yielded significant results for two values. A significant correlation was found with the amount of pain considered normal to master an instrument and psychological dysfunction (Question 10). The value regarding the degree of pushing oneself to physical and psychological limits (Question 12) also showed a significant positive correlation to psychological dysfunction. The values which did not reach significance when correlated with the dysfunction levels were: interference with personal and social needs, and sacrificing personal time to prepare for a performance. However, the four values combined demonstrated significant correlations with an increase in both physical and psychological dysfunction. (see Table 16).

The third research question asked if there was a significant correlation between the collective values regarding effort and sacrifice and practice-related habits. The null hypothesis related to this question was: There will be no significant relationship between the collective values of professional musicians regarding effort and sacrifice and

a) an increase in time spent in individual practice per week (Question 5).

b) an increase in the length of practice session without taking a break (Question 6).

c) an increase in the number of hours spent in playing-related work (Question 7a). 
To test this hypothesis, the combined values of Questions $8,10,11$, and 12 were correlated with Questions 5, 6, and 7a, respectively. Each correlation yielded significant results. 


\section{CHAPTER 5}

\section{SUMMARY, DISCUSSION AND IMPLICATIONS FOR THE PROFESSION}

\section{Summary of Research Questions and Hypotheses}

The results of this study to investigate whether a significant relationship exists between selected habits and values of instrumental musicians and the degree of reported physical and psychological problems has yielded results that provide evidence for continued research and support for the role of occupational therapy with this population.

\section{Discussion of Demographic Results}

The majority of participants in this study reported combining their music-related work with other types of employment. The average participanat worked close to four hours in playing-related work and close to six hours in other work, which yielded a total of ten hours of work per day. The mean hours spent in leisure/socialization time seemed fairly generous ( 2.5 hours per day), but the participants may have included in this category time that was not assigned to any other category, such as driving time. 


\section{Discussion of Other Findings}

Ninety-two percent of the participants of this study reported having some type of physical symptom, with $63 \%$ reporting the presence of a psychological symptom (see Tables 11 and 12). The study involving the International Conference of Symphony \& Opera Musicians (ICSOM) revealed that $82 \%$ reported a medical problem of some kind at the time of taking the survey (Fishbein, et al., 1988). While the percentage of physical symptoms reported in the current study was higher, this discrepancy may be due to the inclusion of problems experienced in the last six months.

The most common physical symptoms reported in this study were neck, back, and shoulder pain. This is similar to the most frequently reported symptoms from Dezell's study in 1987, and also similar to results from Caldron's study (1986). Caldron found in studying 250 high level musicians, that back pain, neck pain and muscle spasms were the most commonly reported physical complaints relative to playing musical instruments. The ICSOM study (Fishbein, et al., 1988) also found the most commonly reported locations of musculoskeletal problems were the shoulder, neck, and back.

The most frequently reported psychological symptoms in this study was restlessness (32\%), followed by acute anxiety and sleep disorders. In Dezell's study, restlessness was also the most frequently reported psychological complaint (42\%). The frequency of reported stage fright symptoms was surprisingly high, with $63 \%$ claiming one or more stagefright related symptoms (Table 13). 
In spite of a high percentage claiming physical problems, more than half of all respondents did not indicate any time lost from performing, and therefore their "physical dysfunction index" was low. Many participants also reported psychological symptoms without any indication of severity (i.e., time lost from performing). It is surmised that some may have been unaware of the effect of the problem on their performance, or on their potential. For example, a bass player may have adapted to having back pain after an hour of practice, and would not report time lost from playing if he or she did not have this symptom. The resulting physical or psychological dysfunction index would be scored as a zero, indicating no dysfunction, in spite of the presence of a symptom for a specified number of weeks. The large percentage of zero scores skewed the normal distribution for Questions 13 and 14, which provided the measure of physical and psychological dysfunction.

The values regarding effort and sacrifice which were reported reflect a group of intense, hard-working people. The average number of hours worked per day (playing-related work and other work) was 10.04. As a group, this sample reflected the general belief that one must undergo some pain and sacrifice to reach one's goal. The amount of interference with personal and social needs, on a scale of one to five, was 2.74 , indicating that some sacrifice of personal time was expected (Question 8). One musician in his early twenties reported that playing his instrument caused a great deal of interference, adding this comment: "Let's just say it's torpedoed most of my relationships!" 
The average amount of pain considered "normal" to master an instrument (Question 10) was 2.29, indicating some pain was considered normal. The average amount of personal time lost to accommodate practice prior to a concert or audition was 3.27 , indicating that $40-60 \%$ of personal time was lost (Question 11). This question received a higher rating on the Likert scale than Question 8, probably due to the specific description of the extra demands a musician must deal with in preparation for a performance. The average value of pushing to one's limits (Question 12) was 3.25 , indicating that the majority felt that their musical pursuits required a lot of effort, both physically and psychologically.

There were differences between the findings of this study and the results from Dezell's study in 1987, some of which are due to a slightly different population being surveyed. In Dezell's study, the average of daily hours spent playing instrument was 4.3 , and an average of 4.8 hours was spent in non-music related work. The participants in the 1987 survey reported a slightly higher presence of physical or psychological problems (94\%). The mean value of "pain considered normal" was very similar to the resulis from the current study, however. In response to the question regarding how much personal time was sacrificed to accommodate practice, the participants in Dezell's study reported a mean of 4.09 (on a one to five scale), indicating "more than an average amount" of personal sacrifice was made for practicing. The current study yielded a mean of 3.27 for this value. The mean value of "pushing to one's limits" from Dezell's study was 3.78 , which was slightly higher than the mean of 3.25 from the current study. These values were slightly higher, due perhaps to 
a higher percentage of paid professional musicians in Dezell's sample. It could also be possible that during the two to three years between the surveys, some of the musicians' attitudes toward pain and sacrifice had become more realistic.

Dezell's study concluded that both a high level of dysfunctional role perceptions and a high level of physical and psychological disabilities existed in the professional musician population. For example, subjects with a higher acceptance of suffering reported higher incidence of back pain and higher incidence of muscle cramping. However, the null hypotheses were not rejected since the correlations were not statistically significant. With the addition of duration and severity parameters for physical and psychological dysfunction in the current study, and additional definition of the hypotheses, some correlations were achieved.

The testing of the first hypothesis demonstrated a significant correlation between an increase in dysfunction and an increase in the number of hours spent playing one's instrument in an average day, a decrease in leisure or socialization time, and a decrease in time spent sleeping. However, no significant correlation was found between an increase in dysfunction and an increase in the length of practice time without taking a break, nor was a significant correlation found between an increase in dysfunction and a decrease in exercise. Therefore, three of the five substatements of the null hypothesis were rejected. It is surmised that the other substatements of the null hypotheses were not rejected due to the majority reporting zeroes for the dysfunction indexes. These results suggest that there is a need for balance in one's work, leisure, self-care, 
and rest. The advice given by Fry (1986b) regarding optimum practice habits is substantiated by the significant correlations. He recommended a practice session of 25 minutes with a five minute break, contending that the muscles would be more responsive after the break, and thus the quality of practice would be better.

The results of the testing of the second hypothesis demonstrated that an increase in psychological dysfunction was significantly correlated with an increase in the amount of pain considered to be normal, and an increase in pushing to one's limits. The values of sacrificing personal time and interference with personal and social needs were strongly associated with an increase in dysfunction, as illustrated by Figure 4, but were not found to be statistically significant. When considered aggregately, however, the four values of effort/sacrifice significantly correlated with an increase in physical and psychological dysfunction, thus permitting rejection of the second null hypothesis.

Testing of the third null hypothesis yielded statistically significant results demonstrating a correlation between effort and sacrifice and time spent in practice per week, length of practice without a break, and an increase in hours spent in playing-related work. These results confirm Kielhofner's theory of how the volition subsystem dealing with beliefs and values affects the habituation subsystem which refers to habits and roles. It may be that one cannot make changes in one subsystem without addressing the other. 


\section{Applying the Model of Human Occupation}

The Model of Human Occupation provides a consistent way of conceptualizing occupational dysfunction and defining the role of occupational therapy in its treatment. The volitional subsystem is comprised of a person's sense of personal causation, values, and interests. Values are images of what is good, right and/or important, and exert a strong influence over choices that a person makes (Kielhofner, 1985). Values govern a person's sense of temporal orientation (beliefs of how time should be used); the meaningfulness of activities, occupational goals, and personal standards. The musician with occupational role dysfunction may feel obligated to fill time with activity, perferably work. His or her goals may be set unrealistically high. A certain competition "must" be won, and high personal standards would rationalize extreme sacrifices. Pain may be ignored or denied.

Through the habituation subsystem, behavior is organized via routines and roles. Imbalances in the habituation subsystem include overrigid internalized expectations, the lack of role balance, and inflexible habits. Expectations of what must be done to be a musician are heavily influenced by family members and early teachers. Yo-Yo Ma once said in an interview regarding his parents: "My parents...wanted the musical excellence to be there. My father wanted control. Maybe the best sentence that would sum him up is that he told me, 'It does not matter what anybody thinks of you, you have to have my approval.' In its best sense, this gives 
me a very self-critical view of myself in anything that I do" (Brandfonbrener, 1986b).

There is a need for a variety of roles in life - some allow one to explore, others to play, and others to pursue competence or achievement (Kielhofner, 1985, p. 27). A musician may have very limited roles in life, having spent many hours in isolated practice to the exclusion of other activities. Habits, by which behavior is organized, may be set too rigidly so break times are not allowed, or a pre-set practice schedule must be met, regardless of fatigue. Habits may be inadequately organized so that selfcare, leisure, or socialization needs are neglected.

The performance subsystem is responsible for directly producing human behavior through the perceptual-motor process. Musculoskeletal problems can arise due to harmful joint positions, excess strain in the manner of holding the instrument, carrying the instrument, or faulty playing technique. Symptoms may be exacerbated by tension and fatigue.

Effective occupational therapy requires all three subsystems to be addressed. Values have a strong influence over habits, as seen from the results of the testing of the third hypothesis in this study. A musician with occupational role dysfunction needs to consider his or her own values and needs. Is the person really receiving that much satisfaction from playing? Is he or she playing to substitute for satisfaction that is lacking from social relationships? Is there a need for more social support? These types of questions may best be addressed within the structure of a supportive group. Kielhofner proposes: "Value change is central to human development. Throughout life persons set new priorities, find new sources of meaning, 
achieve goals and set out to accomplish new ones. Persons are typically aware only of values on reflection, and sometimes must systematically evoke and examine what is important to themselves when making major decisions" (1985, p. 20).

The Occupational Questionnaire developed by Riopel (1981) provides a tool with which the therapist can gain more detailed information about: 1) habits, and the typical use of time; 2) the balance of work, play, daily living tasks, and sleep; 3 ) the amount of personal causation experienced in daily activities; 4) the amount of interest experienced in these activities; and 5) the amount of value experienced in daily activities. This tool might be used to help the musician gain insight into what gives him or her the greatest sense of satisfaction and accomplishment, and also to work towards a better balance between work, rest, and leisure.

\section{The Role of Occupational Therapy}

Occupational therapists are well suited to work with musical clientele, due to their unique knowledge base which includes analysis of activity, problem solving, and achieving a balance in work, self-care, and leisure. It should be understood, however, that occupational therapy is one of several professions which together treat the multi-faceted problems of musicians.

Goodman and Staz (1989, p. 9) list the following services provided by occupational therapists who treat musicians at the Cleveland Clinic Foundation:

1) functional evaluation of the upper extremity; 
2) splinting of the upper extremity;

3) exercise and activity programs (rehabilitative and preventive) to increase strength, flexibility, endurance, dexterity, and coordination;

4) therapeutic use of ice and heat as adjuncts to exercise or performance programs;

5) adaptation of the instrument, playing position, or performance chair;

6) evaluation and adaptation of practice and performance schedule;

7) instruction in preventive activities such as warm-up and cooldown programs to prepare soft tissues for stress;

8) evaluation and adjustment of all activities of daily living which may contribute to the problem;

9) adaptive equipment for activities of daily living (to improve task efficiency and body mechanics for all activities that a musician undertakes throughout the day);

10) education in joint and soft tissue protection techniques;

11) evaluation of psychosocial components such as life stress, time management, performance anxiety, social and interpersonal skills, frustration tolerance, compulsive or obsessive behavior;

12) relaxation training and other techniques to manage physical and psychological stress. 


\section{Evaluation of the Injured Musician}

Information regarding the roles, habits, and values of the client can be gleaned effectively in an interview style during the first visit, or a written questionnaire can be used. It is important to take a thorough history of the problem, and to find out if the client is receiving concurrent therapies from other professionals. The physical examination of a musculoskeletal problem should include the evaluation of range of motion, tendon gliding, pain, edema, sensation, and strength, which of course is tailored to the individual problem.

In many cases it is helpful to observe the individual playing his or her instrument. A variety of passages can be used, both legato and more technically demanding passages. Observe for tension patterns, breathing style, and balance of posture. This can be accomplished in conjunction with the music teacher. A violinist who participated in this study added these comments regarding the importance of proper technique: "Therapy to help heal existing damage can be very helpful, but the root cause of the problem must be addressed, or one simply ends up in an endless pain/therapy cycle. The general rule is: if it hurts, you're doing something wrong. Fix it, and the pain will go away; therapy will help it go away faster!"

Some special considerations for helping the musician return to full capabilities are to incorporate playing the instrument in the strengthening process. The musician may resume playing after an injury in ten or fifteen minute segments, several times a day. It may be a good idea to keep a log 
of these practice sessions, noting discomfort during or following the session.

Occupational therapists who have some musical experience are especially suited to develop liaisons between the medical and musical communities. Workshops geared for the prevention of probiems can be organized in conjunction with local conservatories and music teachers.

Appendix $\mathrm{C}$ includes a partial list of resources for the occupational therapist wishing to develop skills in working with musicians. Works regarding Feldenkrais and Alexander techniques are mentioned, as well as resources which will broaden one's knowledge of the technical aspects of playing an instrument.

\section{Recommendations for Further Research}

Further research is needed to determine effective measures for the restructuring of habits and values of musicians with occupational role dysfunction. The format of interviews or individual case studies would be useful to glean more detailed information and to clarify responses, without misinterpretation of questions which can occur when using survey methodology. 


\section{REFERENCES}




\section{References}

Brandfonbrener, A. G. (1986a). An overview of the medical problems of musicians. Journal of American College Health, 34 (4), 165-169.

Brandfonbrener, A. G. (1986b). Interview with Yo-Yo Ma. Medical Problems of Performing Artists, 1, (3) 69-72.

Caldron, P., Calabrese, L., Clough, J., Lederman, R., Williams, G. \& Leatherman, J. (1986). A survey of the musculoskeletal problems encountered in high level musicians. Medical Problems of Performing Artists, 1 (4), 136-139.

Dezell, C. (1987). Physical and psychological disabilities of professional musicians: A new perspective. Unpublished master's thesis, San Jose State University, San Jose, California.

Fishbein, M., Middlestadt, S. E., Ottati, V., Straus, S. \& Ellis, A. (1988). Medical problems among ICSOM musicians: Overview of a national survey. Medical Problems of Performing Artists, 3 (1), 1-8.

Fry, H. J. (1986a). Incidence of overuse syndrome in the symphony orchestra.. Medical Problems of Performing Artists, 1 (2), 51-56.

Fry, H. J. (1986b). Overuse syndrome in musicians: Prevention and management. Lancet 2, 728-731.

Fry, H. J. (1986c). Overuse syndrome in musicians - 100 years ago. An historical review. Medical Joumal of Australia, 145, 620-625.

Fry, H. J. (1987). Prevalence of overuse (injury) syndrome in Australian music schools. British Journal of Industrial Medicine, 44, 35-40. 
Goodman, G. \& Staz, S. (1989). Occupational therapy for musicians with upper extremity overuse syndrome: Patient perceptions regarding effectiveness of treatment. Medical Problems of Performing Artists, 4 , (1), 9 - 14.

Hamilton, J. (1987). The healthy string player. Strings, 3, 17-21. Harmon, S. E. (1982) Occupational diseases of instrumental musicians Literature review. Maryland State Medical Journal, 31, 39-42.

Kielhofner, G. (Ed.), (1985). A model of human occupation: Theory and application. Baltimore: Williams and Wilkins.

Lederman, R. J. \& Calabrese, L. H. (1986). Overuse syndromes in instrumentalists. Medical Problems of Performing Artsists, 1 (1), 7 11.

Lehrer, P. M., Rosen, R. C., Kostis, J. B., \& Greenfield, D. (1987). Treating stage fright in musicians: The use of beta blockers. New Jersey Medicine, 84 (1), 27-33.

Lockwood, A. H. (1988). Medical problems in secondary school-aged musicians. Medical Problems of Performing Artsists,3, (4), 120132.

Martinsen, W. E., Medhus, A., \& Sandvik, L. (1985). The effects of aerobic exercises on depression: A controlled study. British Medical Journal, 291, 109.

Middlestadt, S. \& Fishbein, M. (1989). The prevalence of severe musculoskeletal problems among male and female symphony orchestra string players. Medical Problems of Performing Artists, 4 (1), p. 41-48. 
Newmark, J. \& Hochberg, F. (1987). Doctor, it hurts when I play:

Painful disorders among instrumental musicians. Medical Problems of Performing Artists 2 (3), 93-97.

Pruett, K. (1986). From a public speech given at a seminar entitled "Playing Hurt" organized by the University of Minnesota and the Minnesota Orchestra.

Revak, J. M. (1989). Incidence of upper extremity discomfort amoung piano students. The American Joumal of Occupational Therapy, 43, 149-154.

Riopel,. N. (1981). An examination of the occupational behavior and life satisfaction of the elderly. Unpublished master's research project, Virginia Commonwealth University.

Spaulding, C. (1988) Before pathology: Prevention for performing artists. Medical Problems of Performing Artists, 3 (4), 135-139. 
APPENDIX A

QUESTIONNAIRE 


\section{QUESTIONNAIRE FOR INSTRUMENTAL MUSICIANS}

IMPORTANT! To facilitate the analysis of your responses, please fill in entire questionnaire. To those questions requiring one response, please limit yourself to one answer. If the categories given are not exact for you, your closest estimate will be helpful. THANK YOU!

1. Gender (Circle the appropriate answer)

Male Female

2. Age (Write your age in the space provided.)

3. Describe your primary role as a musician: (Circle the appropriate answer.)
a. student
b. professional player
c. teacher
d. amateur performer
e. conductor

4. What instruments do you primarily play? (Circle the appropriate answer.)
a. strings
d. percussion
b. woodwinds
e. keyboard
c. brass
h. harp

5. How many hours do you practice individually per week?

6. How long do you usually practice at one time before taking a break? (Circle the appropriate answer.)
a. $0-.5$ hours
d. $1.6-2.0$ hours
b. $.6-1.0$ hours
e. $2.1-3.0$ hours
c. $1.1-1.5$ hours
f. $3.1+$ hours

7. On the average, how many hours per day do you spend in each of the following? Write in the number of hours for each in the space provided. Please check to see that the total number of hours is 24 .

a. playing-related work (practicing/rehearsing/performing)

b. non-playing related work (teaching, employment, housework/child care )

c. meal preparation/eating

d. hygiene/grooming/dressing

e. exercise

f. leisure/socialization

$\overline{24}$ g. Sleeping 
8. To what extent does the time spent playing your instrument interfere with meeting your personal and social needs? (Place an $X$ in the appropriate space below.)

no interference

some

interference a great deal of

9. Have you ever experienced physical pain or weakness while playing? Yes No

If yes, what have you most frequently done first? (Please circle one)

a. increase practice time and content difficulty to overcome it

b. continue, and hope that it will subside

c. decrease time spent in practice, or take more frequent breaks

d. discontinue practice until symptoms disappear

e. seek help from a health professional

10. How much physical pain do you consider normal in gaining mastery of an instrument? (Place an $\mathrm{X}$ in the appropriate space below.)

no pain

average

$\overline{\text { intense pain }}$

11. Prior to an important concert/audition/competition, what percentage of personal time is lost to accommodate practice time?

(Place an $\mathrm{X}$ in the appropriate space below.)

\begin{tabular}{|c|c|c|c|c|}
\hline $\begin{array}{l}\qquad \overline{0-20} \% \\
\text { (all or most } \\
\text { personal } \\
\text { time intact) }\end{array}$ & $2 \overline{0-40} \%$ & $4 \overline{0-60 \%}$ & $6 \overline{60-80 \%}$ & $\begin{array}{l}80-\overline{100 \%} \\
\text { (most or all } \\
\text { personal } \\
\text { time is lost) }\end{array}$ \\
\hline
\end{tabular}

12. Due to rising competition, pressure and high demands that accompany being a professional musician, do you feel you should:

(Place an $X$ in the appropriate space below.)

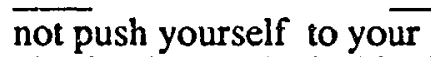

physical/psychological limits push yourself

to your limits 
13. At the column on the left, indicate with an $X$ which of the following symptoms you have experienced in the last 6 months which were caused or aggravated by playing your instrument. Use the middle column to indicate the number of weeks the symptoms lasted. On the right, please indicate how much the problem has prevented you from practicing, playing, or performing based on the percentage of time lost while the symptoms persisted.

Physical Symptoms

headaches

neck pain

shoulder pain

back pain

pain in forearm /upper arm pain in wrist/hand/fingers

tendonitis

skin irritation

tingling/numbness in extremities joint swelling/pain

eye strain

ear problems

other:
No. of Weeks

Symptoms Lasıed

Severity of

Symptoms

(\% of time lost)

14. Please follow the same directions listed for \# 14.

Psychological Symptoms

Symptoms

restlessness

sleep disorders

stomach disorders

eating disturbances

acute anxiety

depression

use of drugs/alcohol

other
No. of Weeks

Symptoms Lasted

\author{
Severity of \\ Symptoms \\ (\% of Time Lost)
}


15. At the column on the left, indicate which of the symptoms you may experience while performing. At the column on the right, please estimate the percentage of accuracy that is lost because of these symptoms.

Stage Fright Related

Symptoms
No. of Weeks

Symptoms Lasted
Percentage of

Accuracy

Lost While

Performing shakiness/incoordination difficulty in swallowing

_ muscle weakness

memory lapses

other

16. How threatening are the previously mentioned symptoms to your career as a musician?

very little

(no worry)

$$
\overline{\text { average }}
$$

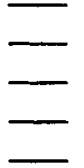

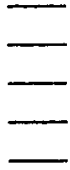




\section{APPENDIX B}

\section{INFORMED CONSENT LETTER}


Dear Musician,

You are invited to participate in a confidential study of the occupational hazards of professional musicians. This study is conducted through the Department of Occupational Therapy of San Jose State University. Through this research, I hope to gain a better understanding of the ways in which occupational therapy can better serve the needs of performing artists.

You are asked to fill out the attached questionnaire which contains information regarding work-related difficulties you may have experienced. Your attitudes as a musician concerning physical and psychological dysfunction related to your occupation are very important for appropriate delivery of services. The total time required is 5 to 10 minutes.

Any information obtained in this study will remain absolutely confidential, and will be used only for the purposes of the study. The collected information, combined with outside research, will be incorporated into the foundation for programs utilizing positioning, muscle strengthening, therapeutic exercise, and treatment designed for the psychological and stress-related needs of individual performing artists.

If you decide to participate, you are free to withdraw your consent at any time without prejudice. Your consent to participate in the study will be indicated by your completion of the questionnaire.

If you have any questions regarding this study, feel free to contact me at (408) 2685839. Complaints about the procedures may be presented to Gordon Burton, Ph.D. (Associate Professor, Department of Occupational Therapy), at (408) 924-3074. For questions or complaints about research subject's rights, you may contact Serena Stanford, Ph.D. (Associate Academic Vice President for Graduate Studies) at (408) 924-2480. Thank you for your valuable time.

Sincerely, Marcia Dyk, OTR 
APPENDIX C RESOURCE LIST 


\section{RESOURCES FOR WORKING WITH MUSICIANS}

\section{Books on Instrumental Playing Technique, Biofeedback, and Movement Awareness}

Collins, P. (1978). The violinist's guide to the Alexander technique. The Strad, October issue.

Feldenkrais, M. (1972). Awareness through movement: Health exercises for personal growth. San Francisco: Harper \& Row.

Hanna, Thomas (1988). Somantics - Reawakening the mind's control of movement, flexibility, and health. Addison-Wesley Publishing Company. (Gives a series of "Somatic Exercises designed to reduce the effects of sensory-motor amnesia; based on the work of Dr. Moshe Feldenkrais.)

Irvine, J. and LeVine, W. (1981). The use of biofeedback to reduce left-hand tension for string players. American String Teacher, 31, 10-12.

Mantel, Gerhard (1975). Cello technique: Principles and forms of movement. Bloomington IN: Indiana University Press. (Discusses all aspects of cello playing, and gives recommendations on technique based on research, experiment, and experience.)

Rolland, P. (1974). The teaching of action in string playing: Developmental and remedial techniques. Urban, IL: Illinois String Research Associates. (Presents physiologically based string pedagogy. Includes "movement training," a program of games 
and exercises designed to free the student from excess tension while performing.

Rosenthal, E. (1987). The Alexander technique - What it is and how it works. Medical Problems of Performing Artists, 2. (3), 53-57.

Szende, O. and Nemessuri, M. (1971). The physiology of violin playing. London: Collet's.

Wolfe, R. (1976). A comparison of self-versus therap:stadministered biofeedback relaxation training and desensitization. Ph.D. dissertation, University of Rochester, New York. (Gives examples of how biofeedback can be applied to performing. 